\title{
Finite dispersal of a separative nepheloid plume by an internal hydraulic jump in a tropical mountainous river estuary
}

\author{
Jiaxue $\mathrm{Wu},{ }^{1,2}$ Lioudmila Ametistova, ${ }^{2,3}$ Malcolm Heron, ${ }^{4}$ Charles J. Lemckert, ${ }^{5}$ \\ and Patrice Kalangi ${ }^{4}$ \\ Received 20 November 2005; revised 3 July 2006; accepted 20 July 2006; published 7 November 2006.
}

[1] This paper investigates the dynamics of an internal hydraulic jump in a river plume and associated suspended sediment dispersal. Field investigations were undertaken into the river plume generated by the Herbert River, Australia, following a moderate flood event induced by Cyclone Fritz in 2004. The forced plume experiences an abrupt transition from supercritical to subcritical via an internal hydraulic jump, as defined by a mode-1 internal Froude number computed using the phase speeds from the TaylorGoldstein equation. The hydraulic theory of a two-layer stratified flow was used to identify the plume shape and the mechanical energy loss within the jump. The hydraulic jump energy loss is primarily transferred to the buoyancy-driven potential energy, uplifting the river plume. Intense stratification decreases the bottom stress, damping the resuspension. Therefore, a separative nepheloid dispersal system occurs at the jump section. Both the upper and lower nepheloid flows are confined to the inner shelf, but have different dispersal behaviors and mechanisms. The upper nepheloid flow, which is primarily controlled by advection and settling, satisfies an exponential decay law of the total suspended sediment concentrations versus the offshore distance. The lower nepheloid flow dominated by deposition is detached seaward near the lift-off point of the river plume. A turbidity front associated with the jump may accumulate a large quantity of suspended sediments, enhancing sediment release from the river plume. These findings will promote in-depth understanding of both the cross-shelf sediment dispersal and muddy deposit on the shelf.

Citation: Wu, J., L. Ametistova, M. Heron, C. J. Lemckert, and P. Kalangi (2006), Finite dispersal of a separative nepheloid plume by an internal hydraulic jump in a tropical mountainous river estuary, J. Geophys. Res., 111, C11004, doi:10.1029/2005JC003404.

\section{Introduction and Background}

[2] Fine-grained sediment exported from an estuary is widely acknowledged to be trapped on the continental shelf in various deposition patterns. Mud accumulation patterns on shelves are present as (a) coastal accumulations, (b) nearshore mud belts bounded landward and seaward by sands, (c) midshelf deposits similarly bounded, (d) outer shelf mud belts, and (e) mud blanket deposits across the shelf mainly off delta [McCave, 1972]. Although many of the processes responsible for muddy deposits are known in general terms, details of their formation are far from clear. Of key importance is the trajectory of riverine sediments in the buoyant plume [Morehead and Syvitski, 1999], and the

\footnotetext{
${ }^{1}$ State Key Laboratory of Marine Geology, Tongji University, Shanghai, China.

${ }^{2}$ Ocean Technology Group, University of Sydney, Sydney, New South Wales, Australia.

${ }^{3}$ Now at FRECOM Ltd, Moscow, Russia.

${ }^{4}$ Marine Geophysical Laboratory, James Cook University, Townsville, Queensland, Australia.

${ }^{5}$ Griffith School of Engineering, Griffith University Gold Coast Campus, Queensland, Australia.
}

Copyright 2006 by the American Geophysical Union. 0148-0227/06/2005JC003404\$09.00 correlation between river plume sediment and deposited sediment [Kineke et al., 2000]. Attempts to systemize river outflow processes into archetypical river mouth dispersal systems are presently still inadequate to explain the dispersal of sediment from the world's major rivers, especially from sediment-laden tropical rivers [Wright and Nittrouer, 1995]. The tropical setting causes many of the coastal processes to be fundamentally distinct from those operating in temperate and polar regions [Nittrouer et al., 1995; Nittrouer and DeMaster, 1996]. Milliman and Syvitski [1992] estimated that approximately 10 billion metric tons of sediments are transported annually by rivers to continental shelves, with small mountainous watersheds supplying the major fraction. Due to their small drainage basins and intense precipitation events, these watersheds tend to have episodic floods which deliver pulses of sediment to the ocean [Hill et al., 2000]. However, the dispersal of flood sediment from small river systems is poorly understood [Wheatcroft et al., 1997].

[3] There are two predominant mechanisms by which sediments move off and along the shelf [Johnson et al., 2001; Wright et al., 2001; Walsh and Nittrouer, 2003]. The primary cross-shelf dispersal is related to a direct fluvial or estuarine sediment supply and may take place in the form of 
river plumes (near the surface) or as turbidity currents due to the rapid settling of sediment. The secondary mechanism is the resuspension and subsequent advection of bottom sediments. Sediment trapping in estuaries and on the inner shelf may be caused both by frontal zones and by the wave boundary layer, forming high concentration layers adjacent to the bed [see Geyer et al., 2004]. The high concentration layers can attain excess densities large enough to initiate down-slope motion on the continental shelf, resulting in an important cross-shelf transport process.

[4] The small mountainous river of Herbert, Queensland, Australia, discharges into the central section of the environmentally significant Great Barrier Reef (GBR) lagoon. The muddy deposits originating from the river are confined to the inner shelf as a shore-parallel mud belt [Larcombe et al., 1995; Larcombe and Woolfe, 1999; Orpin et al., 1999; Lambeck and Woolfe, 2000; Woolfe et al., 2000]. The mud belt belongs to Type $b$ in the McCave's classification system, characterized by nearshore mud belts bounded landward and seaward by sands. Supply, transportation and fate of terrigenous sediment entering the GBR lagoon have become a focus of recent studies, and represent an ongoing environmental concern [Orpin et al., 1999]. The rate of terrigenous sediment supply to the central GBR coastline has probably increased in the last 200 years due to human impact on the catchments of central Queensland [Larcombe and Woolfe, 1999; Neil et al., 2002; McCulloch et al., 2003]. This has led some researchers and environmental managers to conclude that corals within the GBR are under threat from increased turbidity and sedimentation [Anthony, 1999; Fabricius and Wolanski, 2000]. However, geological data and information on sedimentary processes by Larcombe and Woolfe [1999] showed that turbidity levels and sediment accumulation rates at most coral reefs will not be increased, because these factors are not currently limited by sediment supply. How and where the riversupplied sediments are dispersed to the lagoon is closely associated with the GBR health. Three possible dynamic structures or processes have been proposed for controlling the sediment dispersal and deposition patterns: (a) river plume [Wolanski and Jones, 1981; Orpin et al., 1999], (b) a dynamic front on the midshelf [Belperio, 1983; King, 1994; Larcombe et al., 1995], and (c) a coastal boundary layer [Belperio, 1983; Orpin and Ridd, 1996; Lambeck and Woolfe, 2000]. How those structures or processes control the sediment dispersal and further a shore-parallel mud wedge is still unclear.

[5] The objective of this study was to verify the following issues in the coupled small estuary and narrow shelf system: (a) to understand the river plume structure and the sediment dispersal pattern; (b) to examine the occurrence of an internal hydraulic jump and its controlling on sediment dispersal; and (c) to identify the fate and the mechanism of the cross-shelf sediment dispersal.

[6] The structure of this paper is as follows. The geography and setting of the study area are introduced in section 2, and the measurement methodology is described in section 3. Field results on dynamical structures and processes are presented in section 4, including river plume, tidal and subtidal flows and estuarine fronts, bottom shear stresses, and sediment dispersal pattern. Data interpretation is presented in section 5. Theoretical analyses and their compar- isons with data are shown in section 6, and conclusions are made at the end.

\section{Study Area}

[7] The study site for this investigation was based around the mouth of the Herbert River, which is located in North Queensland, Australia, and discharges into the central GBR lagoon (Figure 1a). The Herbert River catchment is the largest of the wet tropics catchments in North Queensland, with a coverage area of $9800 \mathrm{~km}^{2}$. The annual mean discharge is $4 \mathrm{~km}^{3}$, the rainfall is $1500 \mathrm{~mm}$, the runoff is $400 \mathrm{~mm} / \mathrm{m}^{2}$, and the ratio of runoff to rainfall is $27 / \mathrm{m}^{2}$ [Bartley et al., 2003, Table 1]. Approximately $6.8 \times 10^{5}$ tonnes of sediment are estimated to deliver to the estuaries and coastal region each year [Bartley et al., 2003, Table 9].

[8] The Herbert River discharge is highly episodic and strongly seasonal. Dry and wet seasons are distinct and large wet season flood events are associated with tropical cyclones and monsoonal rainfall [Mitchell et al., 1997; Mitchell and Furnas, 1997]. These high-discharge events are an important control on the sediment supply to the shelf [Wolanski, 1994]. Only the higher flows (larger than $12 \mathrm{~m}^{3} / \mathrm{s}$ ) are considered important for estimating suspended sediment load. A log regression relationship was applied to the total suspended sediment concentration (TSS) samples taken at flows greater than $12 \mathrm{~m}^{3} / \mathrm{s}$ [Bartley et al., 2003, p. 38]: $T S S=a Q^{b}$, where $a=0.042, b=0.66, T S S$ is in $\mathrm{mg} / \mathrm{L}$, and $Q$ is the river discharge in ML/day.

[9] The central GBR shelf contains three shore-parallel sedimentary belts [Belperio, 1983; Larcombe and Carter, 2004]: an inner shelf zone of terrigenous sedimentation at depths of $0-22 \mathrm{~m}$; a middle shelf zone of sediment starvation at depths of $22-40 \mathrm{~m}$; and an outer shelf reef tract with its inner edge at ca. $40 \mathrm{~m}$ depth. The inner shelf is dominated by tidal currents, winds and storm waves, and the deposited materials are largely terrigenous (less than 30\% carbonate) [Belperio, 1983]. Within this zone sediment is partitioned into a series of shoreattached or shore-detached mud wedges [Belperio and Searle, 1988].

\section{Methods}

\subsection{Field Observations and Sampling}

\subsubsection{Velocity Profiles}

[10] A RDI $1200 \mathrm{kHz}$ up-looking broadband acoustic Doppler current profiler (ADCP) was deployed at two sites, one deployment at the end of the Lucinda Pier (Site J7 in Figure 1b), the other at mid-Pier (Site J2 in Figure 1b). Surveying at site J7 started at 1045 on 16 February and ended at 1525 on 18 February 2004, covering two tidal cycles in the intermediate period between the spring and neap tides. Surveying at site J2 started at 1609 on 18 February and ended at 1345 on 20 February 2004, covering four hours less than two tidal cycles in the spring. The ADCP profiling interval was set to $120 \mathrm{sec}$, with a vertical resolution (or a bin size) of $0.25 \mathrm{~m}$ and the $1 \mathrm{st}$ bin sampling at 0.82 meters above bed (mab). The water surface can be clearly identified from the intense reflective interface between the water and the air under the calm weathers. 

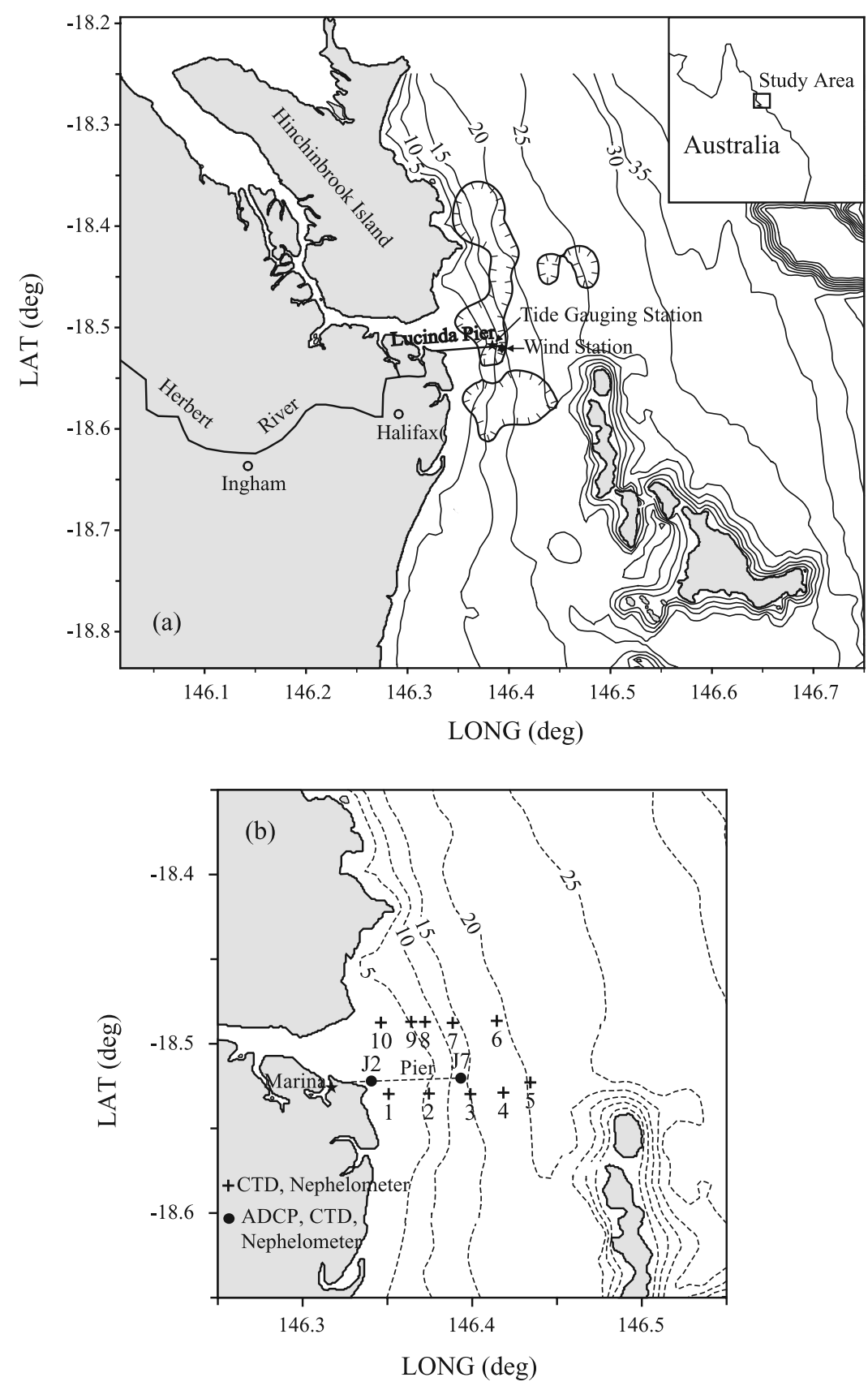

Figure 1. Study area and observation sites. Hatched regions in Figure 1a indicate the muddy zone off the Herbert River mouth. Isobaths are in meters.

\subsubsection{Mooring CTD and Nephelometer Observations}

[11] A Sea-Bird SBE 19 CTD (conductivity-temperaturedepth) was used to measure the profiles of temperature, salinity and pressure (converted to depth) at the site $\mathrm{J} 2$ and $\mathrm{J} 7$ (Figure 1b), approximately $2 \mathrm{~km}$ and $6 \mathrm{~km}$ seawards from the river mouth, respectively. The CTD sampling rate was set to 2 samples per second when it was steadily lowered from the surface to the bottom. The first set of CTD profiling was undertaken at Site J7 on 18 February 2004, beginning at 0820 and taken at a 20 -minute interval until 1520. The second CTD profiling was performed at Site J2 on 19 February 2004, beginning at 0840 and taken at a 20-minute interval until 1500. Turbidity profiling was simultaneously undertaken using a calibrated NEP160 turbidity meter (McVan Instruments PTY LTD) with its wavelength of $860 \mathrm{~nm}$. The turbidity meter was lowered approximately in a half-meter to one-meter intervals from the surface to the bottom.

3.1.3. Shipboard CTD and Nephelometer Observations

[12] Water column profiling for salinity, temperature, and turbidity was made using an Ocean Sensors OS200 CTD and a NEP160 turbidity meter. Moving shipboard measurements were conducted along the southern and northern transects off the river mouth during the flood tide 17271754 on 19 February and during the ebb tide $1157-1347$ on 20 February 2004, respectively. A total of ten sites were 


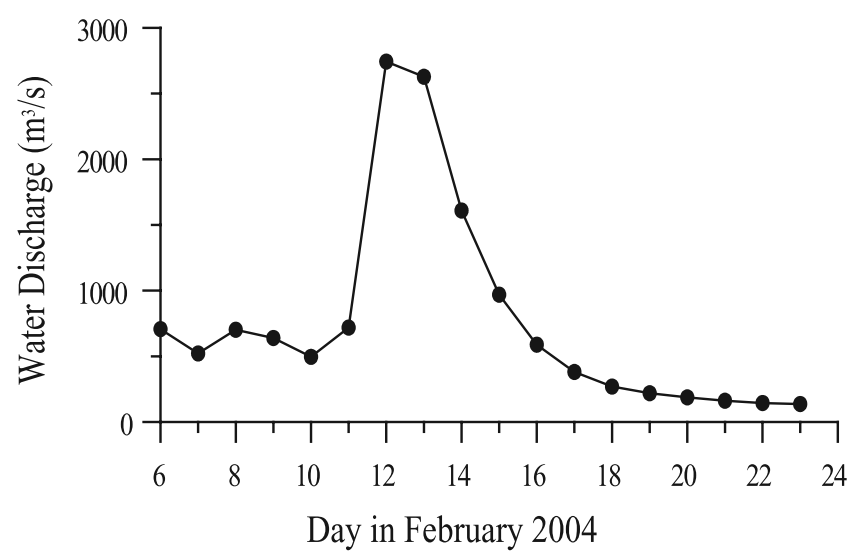

Figure 2. River discharge $\left(\mathrm{m}^{3} / \mathrm{s}\right)$ at the Ingham gauging station in 6-23 February 2004. Data were recorded in a daily-averaged interval (data provided by the Queensland Department of Natural Resources, Mines and Energy).

selected along the two transects, extending from the river mouth to the $20-\mathrm{m}$ isobath (Figure $1 \mathrm{~b}$ ). Turbidity profiling was simultaneously carried out from the sea surface to the bottom in a half-meter to one-meter intervals.

[13] Fluid density $\rho$ in $\mathrm{kg} / \mathrm{m}^{3}$ unit was calculated from the CTD measurements using the equation of state of sea water [Fofonoff, 1985], with the density anomaly defined as $\sigma_{t}=$ $\rho-1000 \mathrm{~kg} / \mathrm{m}^{3}$. The turbidity data taken simultaneously with the CTD measurements were calibrated in the field and converted to TSS using filtered surface-water samples over a range of concentrations. This relationship may not apply to the bottom layer, so we still use the turbidity values to understand the structures of suspended particle distributions in the following presentations.

\subsection{Additional Data Collection}

[14] The Herbert River discharges at the Ingham Pump Station (Figure 1a) were collected in a daily-averaged interval during 6-23 February 2004. Tidal readings (720 February 2004) at the Offshore Lucinda Storm Surge station about $6 \mathrm{~km}$ seaward from the river mouth were provided by the Tidal Unit, Maritime Safety Queensland, Brisbane. The station datum is the lowest astronomical tide, with a reading interval of $10 \mathrm{~min}$. Hourly wind speed and direction were recorded at the end of the Lucinda Pier (32141 Lucinda Point) supervised by the Bureau of Meteorology. Additionally, grain-size composition data from sediment samples collected by Woolfe et al. [2000] were used to show the distribution of the muddy belt.

\section{Results of Observations}

\subsection{Characteristics of River Discharge, Winds, and Tides}

[15] The Herbert River is greatly influenced by transient floods induced by tropical cyclones. During the study period a 3-day flood event occurred in the river as the result of significant rainfall from Tropical Cyclone Fritz (Figure 2). The flood peaked at Ingham at $2743 \mathrm{~m}^{3} / \mathrm{s}$ on 12 February 2004, a moderate flood in the Herbert River catchment. The time lag of the coastal response to the flood peak at Ingham was not definitely clear, but lowsalinity waters were still observed off the river mouth on 20 February, a week after the flood peak passed by the Ingham station.

[16] Wind data at the Lucinda Point during 1620 February showed prevailing south-easterly winds with a dominant wind speed of approximately 5-6 m/s, which are the normal trade wind in this area (Figure 3 ).

[17] Tide harmonic analyses of the tidal level over an entire spring-neap cycle (7-20 February 2004) at the Offshore Lucinda Storm Surge station were conducted with 13 tidal constituents (MS0, O1, P1, K1, MNS2, MU2, N2, M2, S2, 2SM2, MN4, M4, MS4). The analytical form had less than $4 \%$ rms difference from the original signal. Major tidal constituents were $\mathrm{M} 2, \mathrm{~S} 2, \mathrm{~K} 1, \mathrm{~N} 2, \mathrm{O} 1$ and $\mathrm{P} 1$, ordered in a decreasing amplitude. The most important astronomical tide was the $\mathrm{M}_{2}$ lunar semidiurnal constituent, with its period of $12.42 \mathrm{~h}$, amplitude of $0.75 \mathrm{~m}$ relative to mean water level of $1.96 \mathrm{~m}$ above the local datum, and local phase

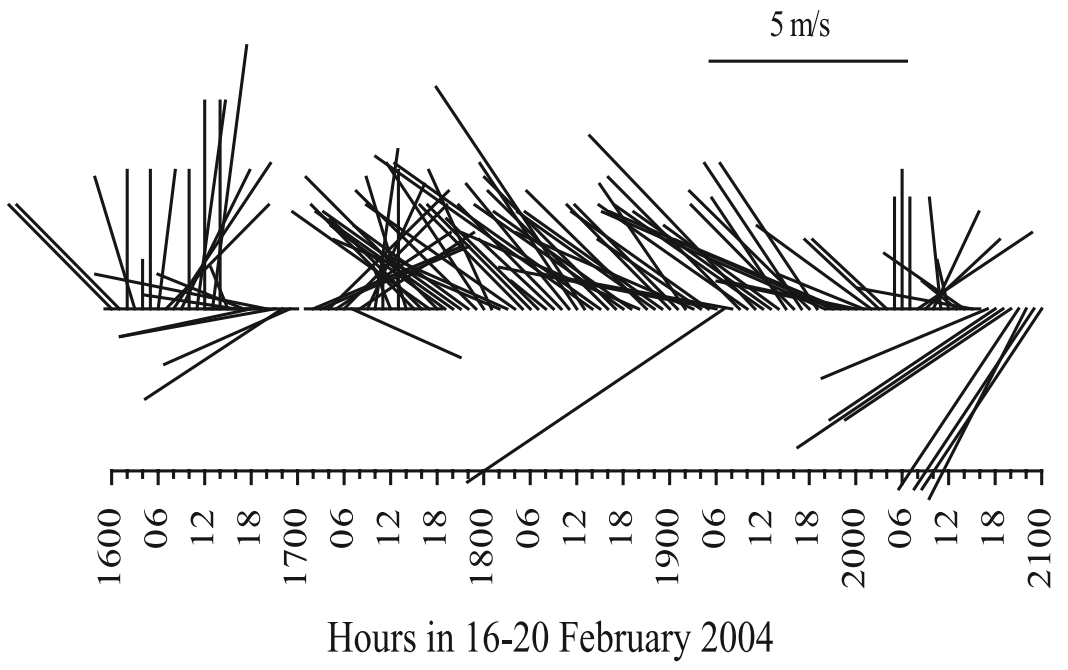

Figure 3. Wind speed vectors measured at the end of Lucinda Pier from 0000 on 16 February to 2300 on 20 February 2004. Starting point of the vector is on the horizontal line. 


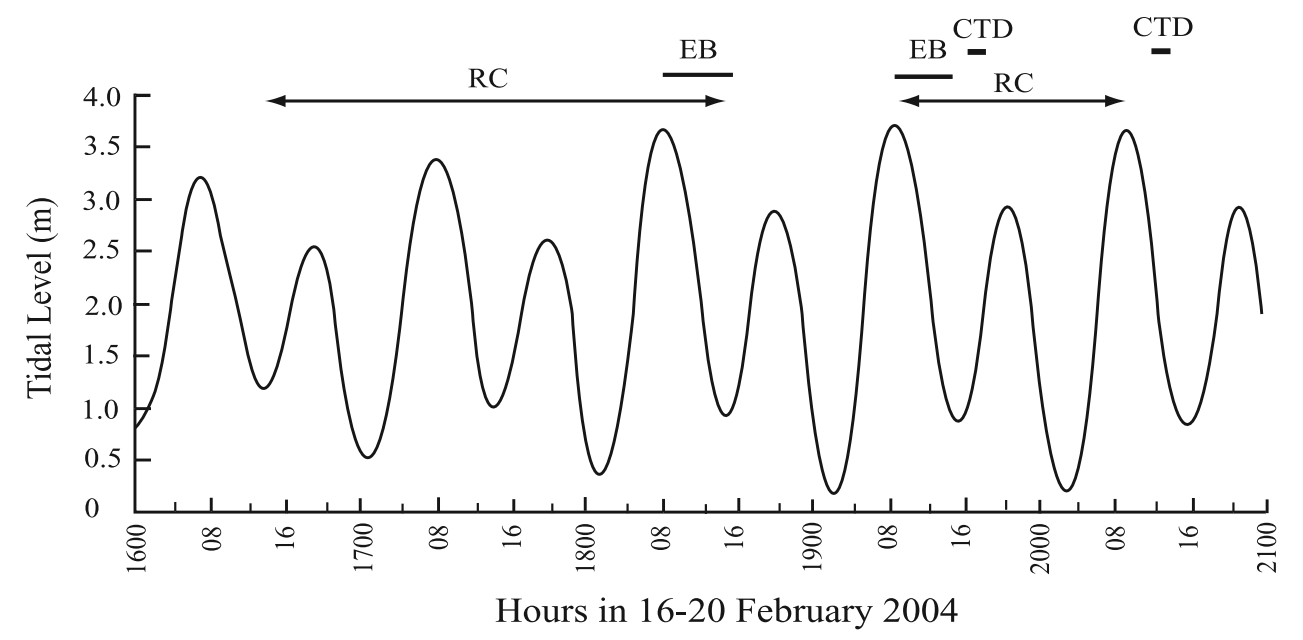

Figure 4. Tidal level at the station of Offshore Lucinda Storm Surge. The tidal datum is the lowest astronomical tide. CTD indicates the surveying period along two transects in Figure 5, EB indicates the ebb tide period for density and turbidity variation in Figure 6, and $\mathrm{RC}$ indicates the period for tidally averaged velocities in Figure 7.

lag of 282.6 degrees. Note that the in-situ surveys were carried out in the spring tide (Figure 4).

\subsection{Cross-Shelf Structures of the Herbert River Plume}

\subsubsection{Density Distributions}

[18] Isopycnals along two transects in the flood tide on 19 February and in the ebb tide on 20 February 2004, showed that large parts of coastal waters are highly stratified (Figure 5a). If the isopycnal of $21 \mathrm{~kg} / \mathrm{m}^{3}$ was assumed to indicate the base of river plume, the plume thickness was nearly constant seawards of the lift-off point, where the plume was detached from the bed. The density difference between the plume and the low-lying coastal waters was approximately $3 \mathrm{~kg} / \mathrm{m}^{3}$ and $2 \mathrm{~kg} / \mathrm{m}^{3}$ in the flood tide and the ebb tide, respectively. The plume was found to be thicker during the flood tide $(4-5 \mathrm{~m})$ than during the ebb tide $(2 \mathrm{~m})$, the lift-off point was deeper in the ebb tide than in the flood tide, and the plume cross-shelf spread was wider for the deeper lift-off point. Therefore, the spread width was positively proportional to the depth of lift-off point, and inversely proportional to the plume thickness, and thus the lift-off depth is inversely proportional to the plume thickness.

[19] A thermal-like spread [List, 1982] or a pulsed buoyancy current [Rennie et al., 1999] occurred along the north transect during the ebb tide (Figure $5 \mathrm{a}$, the third panel). However, the tongue of low-salinity water was not separated by the offshore wind as described by Rennie et al. [1999], since the onshore trade wind prevailed in the Herbert estuary. The plume lift-off depth differs significantly for tide regimes. In the flood tide, the lift-off depth was equal to the plume thickness (Figure 5a, the first two panels); in the ebb tide it was much larger than the plume thickness (Figure 5a, the last two panels).

\subsubsection{Turbidity Distribution}

[20] Turbidity distributions for the four transects measured with the CTD (Figure 5b) showed that a two-layer separative system occurred, although there was a large difference in magnitude between the surface and lower nepheloid flows for the four cases. High-concentration waters were confined landwards to the lift-off point. The detached nepheloid flow in the lower layer started near the lift-off point, and extended seaward for $1-1.5 \mathrm{~km}$, except for the south transect in the ebb tide, where no detached nepheloid flow was observed. The surface nepheloid flow extended farther than the lower nepheloid flow in the ebb tide.

\subsection{Response of the Herbert River Plume to Tidal Variations}

[21] Moored observations at the site J2 and J7 were both undertaken during the falling tides. Data for the inshore site J2 indicates the near-field behavior of the river plume, while the offshore site $\mathrm{J} 7$ represents the far-field behavior.

\subsubsection{Density Variation}

[22] Density anomalies during the ebb tides had distinct and contrasting patterns at the two sites (Figure 6). Vertically homogeneous profiles predominated at the inshore site $\mathrm{J} 2$, whereas intense stratification occurred at the offshore site $\mathrm{J} 7$. At the site $\mathrm{J} 2$, the isopycnals were depressed and vertical stratification was intensified at slack water; at the higher-speed regime the isopycnal changed to be vertically homogeneous. At the site J7, the isopycnals were raised from the bed and vertical stratification was weakened at slack water; at the higher-speed regime the isopycnals were depressed and the stratification was intensified. Therefore the stratification-destratification cycle has an inverse response to the tidal current regime for the two contrasting sites. In addition, a three-layered structure could be identified, with upper and lower mixed layers separated by the pycnocline. In the mixed layer, the vertical gradient of density was relatively small, controlled by the mixing induced by surface wind stresses, river plume-induced friction or bottom friction.

\subsubsection{Turbidity Variation}

[23] Turbidity data simultaneously measured with the CTD showed the similar patterns as the density anomaly for the two sites (Figure 6). At the site J2, higher turbidity with vertically homogenous profiles occurred at the higherspeed regime and a stronger horizontal gradient was present near the maximum ebb. A maximum turbidity occurred near 
(a) Density (sigma-t)

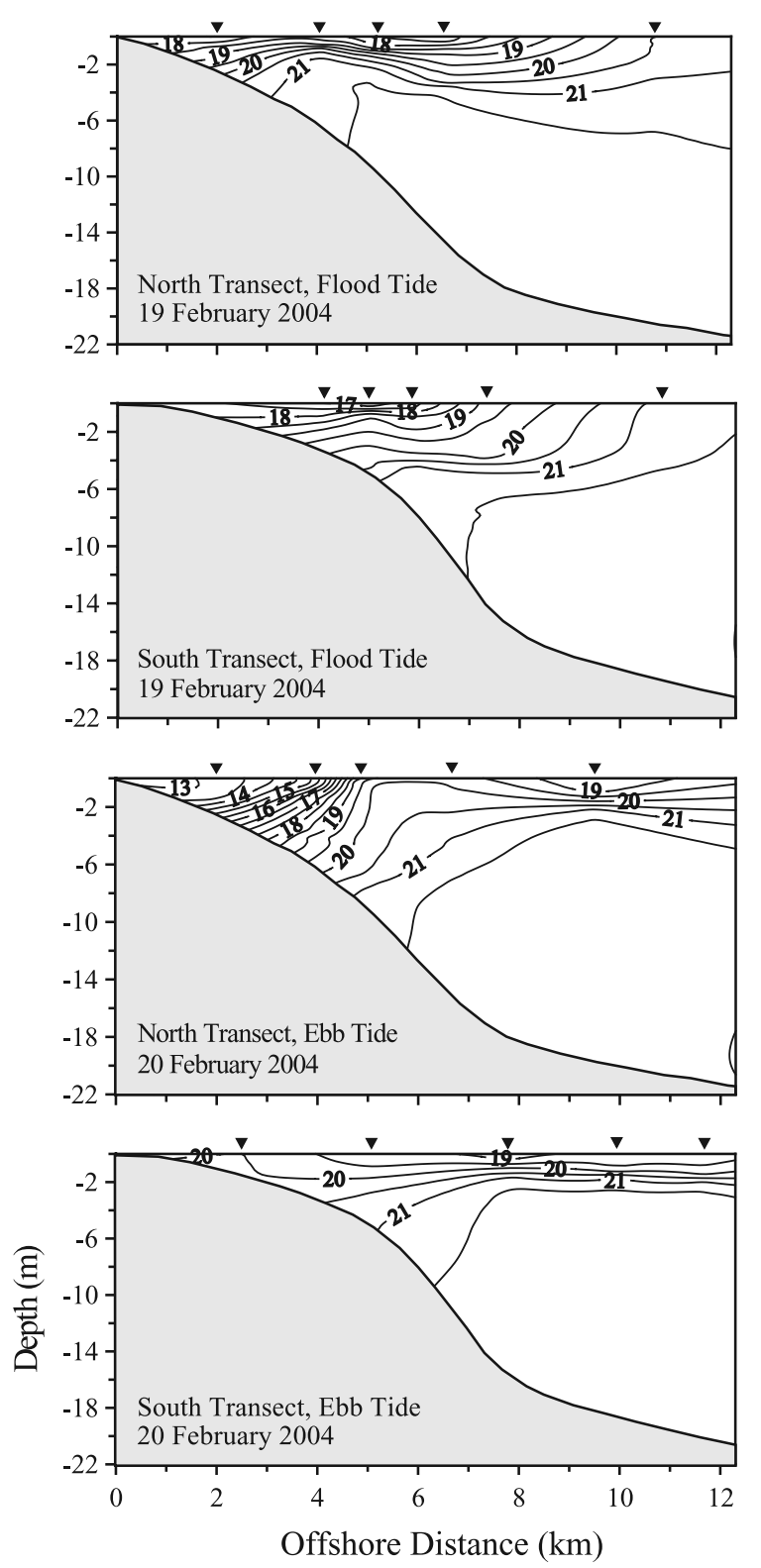

(b) Turbidity
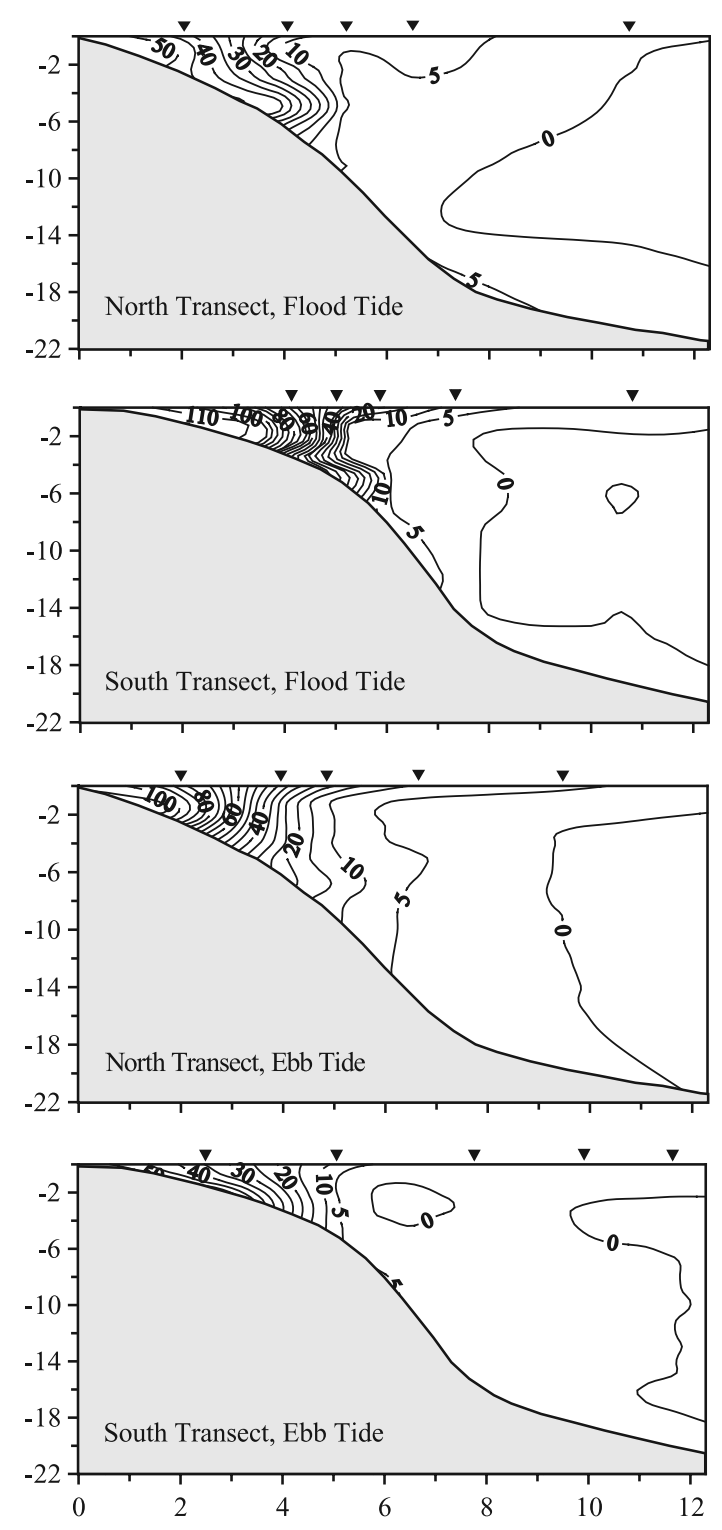

Figure 5. Contouring of (a) density anomaly in $\mathrm{kg} / \mathrm{m}^{3}$ and (b) turbidity in NTU units along two transects during the flood tide on 19 February and during the ebb tide on 20 February 2004, respectively. The triangles on the top of each panel indicate the locations of the CTD and nephelometer profiling.

the bottom close to the maximum ebb. At the site J7, higher turbidity occurred in the upper and lower layers, separated by a low-turbidity layer at middepth where a pycnocline occurred. Higher turbidity near the bed did not occur at the maximum ebb, but rather near the slack water. The thickness of the low-turbidity layer approximated to that of the lower mixed layer.

\subsubsection{Tidal Current Variation}

[24] The cross-shelf velocities had distinct patterns for the two sites (Figure 6), vertically homogeneous at the inshore site $\mathrm{J} 2$ and vertically stratified at the offshore site $\mathrm{J} 7$ with a seaward flow in the upper layer and a landward flow in the lower layer. The along-shelf velocities were vertically separated at the two sites (Figure 6), i.e., higher speed zones at the surface and bottom, respectively, separated by a low-velocity zone at middepth. The contouring of the inversed Richardson number indicated that a supercritical flow predominated at $\mathrm{J} 2$, whereas at $\mathrm{J} 7$ a subcritical flow occurred in the interior, and a supercritical flow existed in the upper and lower layers, respectively.

\subsection{Nontidal Currents in the Herbert River Estuary}

[25] Tidally averaged velocity profiles at the site $\mathrm{J} 2$ and J7 showed the nontidal flow was strongly sheared (Figure 7). The cross-shelf horizontal residual velocity (Figure 7a) showed that a classical two-layered estuarine circulation occurred in the vertical plane. A buoyant outflow moved seawards in the upper layer and a heavier inflow moved 
Site J2
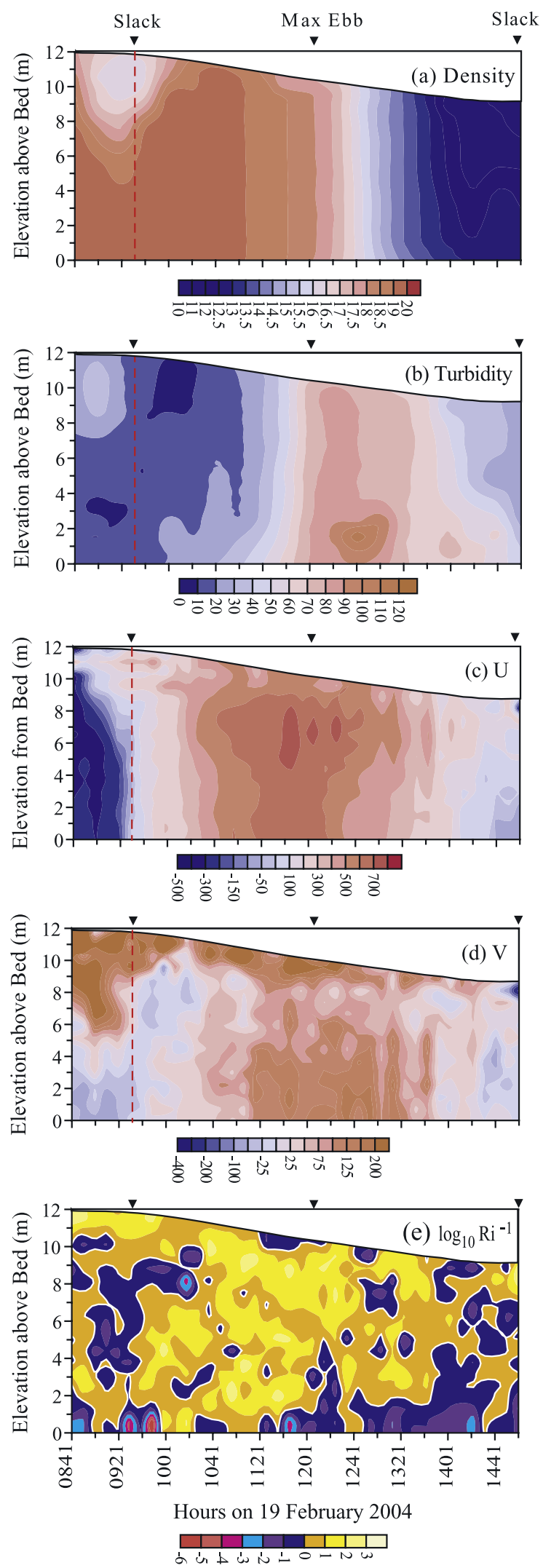

Site $\mathrm{J} 7$
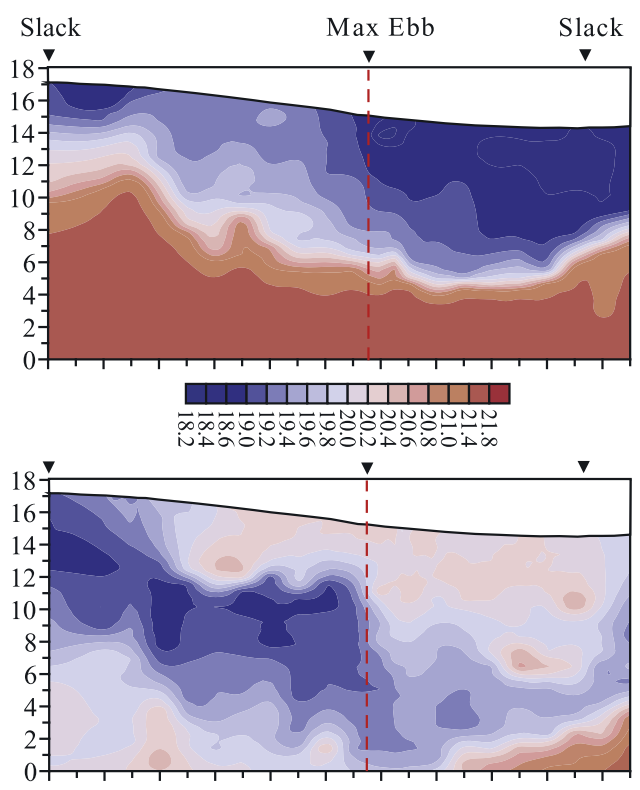

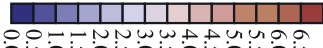
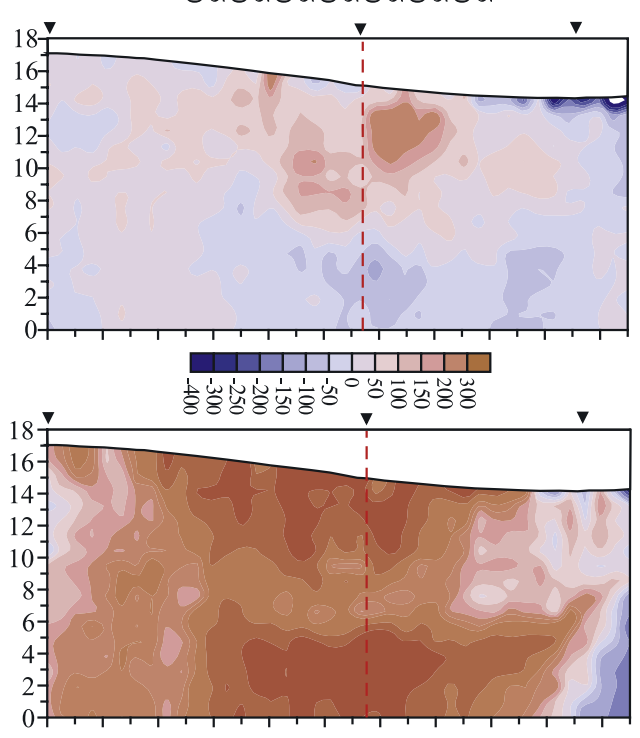

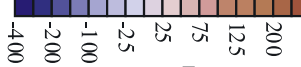
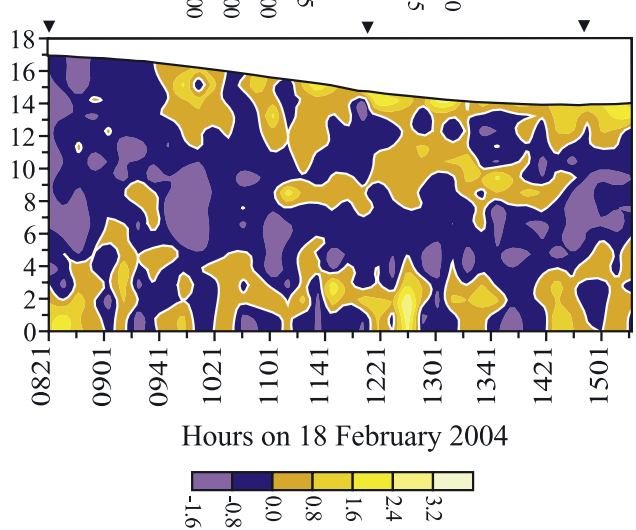

Figure 6. Contouring of (a) density anomaly in $\mathrm{kg} / \mathrm{m}^{3}$ unit, (b) turbidity in NTU, (c) cross-shelf velocity in $\mathrm{mm} / \mathrm{s}$, (d) along-shelf velocity in $\mathrm{mm} / \mathrm{s}$, and (e) the Richardson number at Site J2 (left column) and J7 (right column), respectively. Positive values indicate seaward/northward flows and negative values indicate reverse flows in the velocity panels. 
Site $\mathrm{J} 2$
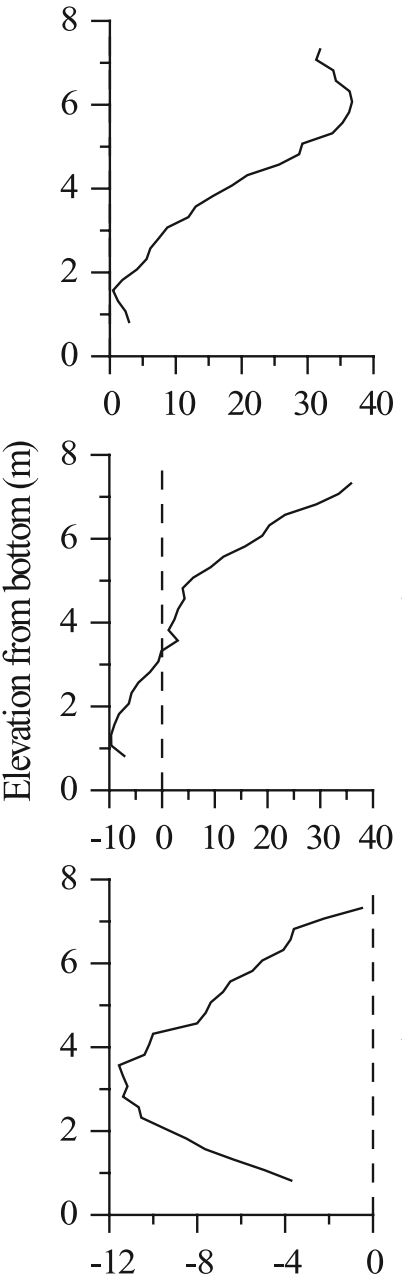

Residual current (mm/s)

Figure 7. Tidally averaged velocity profiles at site $\mathrm{J} 2$ (left panels, from 0841 on 19 February to 0921 on 20 February 2004) and at site $\mathrm{J} 7$ (right panels, from 1331 on 16 February to 1451 on 18 February 2004). (a) Cross-shelf residual velocity $(U),($ b) along-shelf residual velocity $(V)$, and (c) vertical residual velocity $(W)$. Positive values indicate offshore/northward/upward velocities.

landwards in the lower layer, with a null point occurring between $\mathrm{J} 2$ and $\mathrm{J} 7$. The uppermost layer at two sites had an inflow induced by the onshore south-easterly trade wind. The thickness of the benthic inflow decreased landwards from approximately $4.5 \mathrm{mab}$ at $\mathrm{J} 7$ to zero at $\mathrm{J} 2$.

[26] The along-shelf horizontal residual velocity (Figure $7 \mathrm{~b}$ ) showed that a northward flow predominated at both sites. The northward velocity at the surface decreased from the offshore $\mathrm{J} 7$ to the inshore $\mathrm{J} 2$, and subsequently a cross-shelf horizontal gradient of along-shelf velocities existed, resulting in a shear stress along-shelf. The bottom flow was observed to change from the northward flow at $\mathrm{J} 7$ to a southward flow at $\mathrm{J} 2$, indicating the occurrence of a null point between the two sites. Comparing horizontal residual velocity profiles between $\mathrm{J} 2$ and $\mathrm{J} 7$, i.e., in the cross-shelf or along-shelf vertical plane, it is evident that an along-shelf layered flow occurred at $\mathrm{J} 2$, whereas a cross-shelf layered flow occurred at J7. In the intermediate water there was a low-velocity layer, indicating a weak dynamic range in the vertical column.

[27] The vertical velocity (Figure 7c) showed that a downward flow prevailed at the two sites. Maximum vertical velocity occurred in the lower layer at $\mathrm{J} 2$, and it was near the bottom at J7. Combining the cross-shelf velocity with the vertical velocity, i.e., in the cross-shelf vertical plane, a convergent front appears to exist between $\mathrm{J} 2$ and $\mathrm{J} 7$. The convergent dynamic front is an important mechanism for trapping of bottom sediments from both terrestrial and oceanic sources.

\subsection{Estuarine Fronts Within the River Plume}

[28] Following the passing of Tropical Cyclone Fritz, frontal systems with different characteristics were observed in the river plume (Figure 8). Here, a front is defined as a region of rapid change in water properties. Some properties such as density have dynamic consequences, while some such as water color are passive consequences of other processes. Aerial photography images provided the shape, timing and spatial extent of the visible plume front (Figure 8a). Dynamic fronts at the water surface, typically manifest as lines or bands of floating debris (Figure 8b), foam (Figure 8c), distinct changes in the color and transparency of the water (Figure 8d). Mangrove roots were seen at most of the frontal lines (Figure 8f), suggesting a region of downwelling. The detritus line and turbidity line tended to apparently meander as an S-shaped or zigzag curve. The foam line appeared as a straight line parallel to the coastline and was formed by the collision of convergent waters. The biological frontal line looked arc-shaped (Figure 8e).

[29] During the survey at J2, a convergent front with floating debris separated the same water at slack water at 0930 on 19 February 2004 and was driven by opposing tidal currents (Figure 9a). This was a typical tidal intrusion front [see Largier, 1992; Marmorino and Trump, 1996]. Minimum current speed and low turbidity occurred when the frontal line passed by. During the survey at J7, a turbidity front with distinctly different turbidity on both sides was easily seen near the maximum ebb at 1210 on 18 February (Figure 9b). This front had the similar feature as the suspended sediment front observed by Kirby and Parker [1982], in which strong thermohaline gradients were not detected. A larger current speed gradient and a turbidity gradient occurred when the frontal line passed by. Therefore, a sharp gradient of the cross-shelf velocity occurred for the two kinds of fronts described above, but the velocity gradient at $\mathrm{J} 2$ was caused by opposing flows, whereas the velocity gradient at $\mathrm{J} 7$ was apparently associated with a velocity jump.

[30] In summary, the convergent front was an important mechanism for sediment release from the river plume, whereas the turbidity front could accumulate highconcentration sediments on its frontal zone. The maximum TSS value at the frontal line was less than 0.1 to $0.3 \mathrm{~kg} / \mathrm{m}^{3}$, at least one-order smaller than the limited concentration (approximately $1 \mathrm{~kg} / \mathrm{m}^{3}$ ) for the occurrence of convection settling at laboratory [Hoyal et al., 1999; Parsons et al., 2001; McCool and Parsons, 2004], so it might be impossible for convection settling to occur in the river plume. When the 


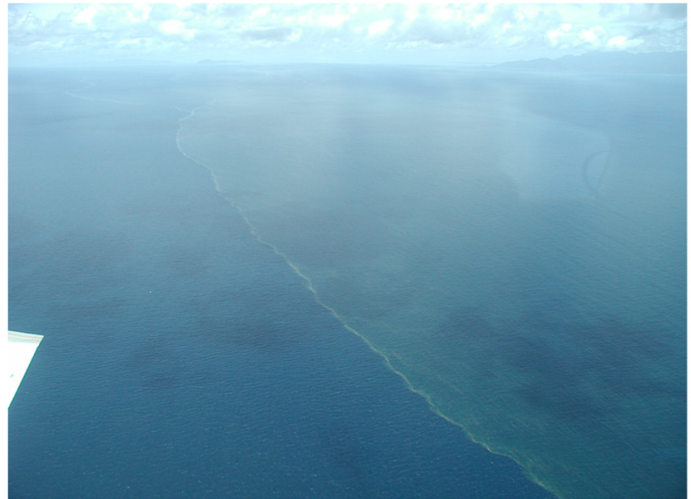

(a)

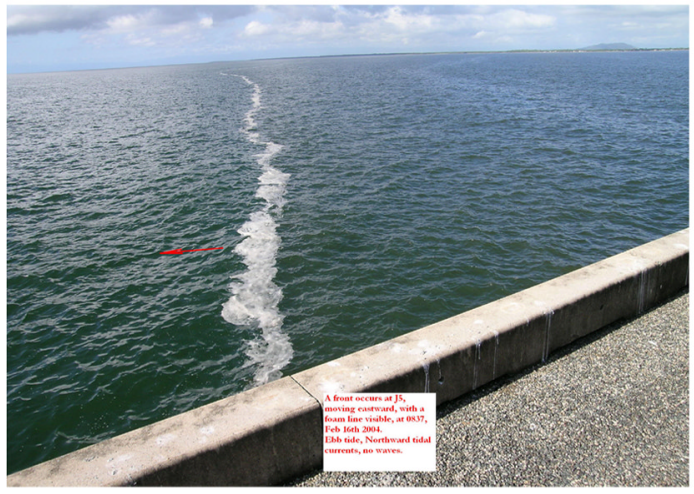

(c)

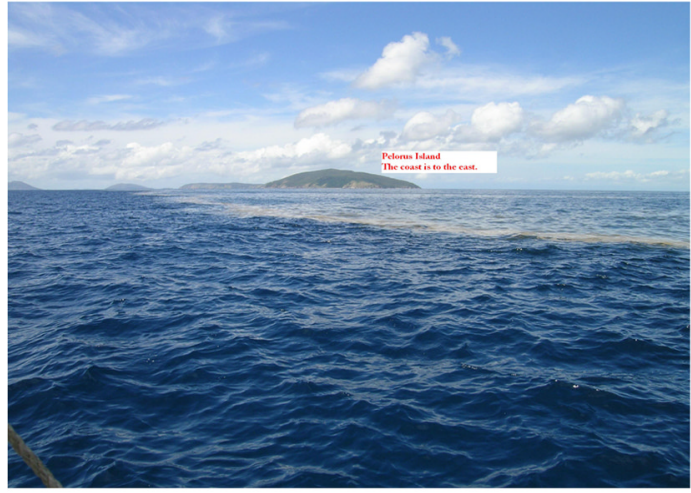

(e)

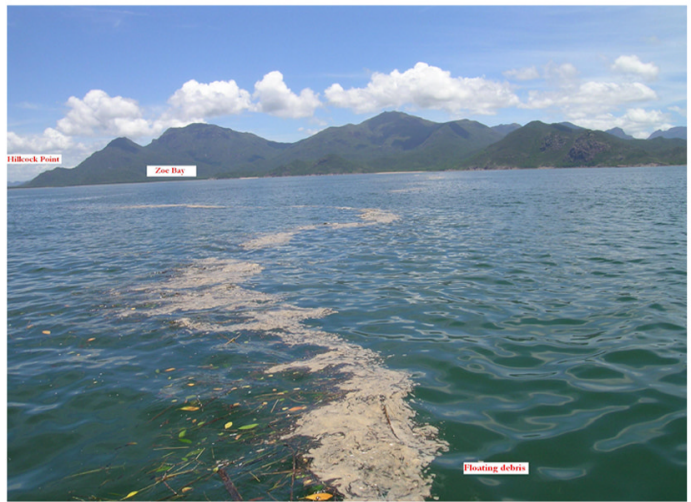

(b)

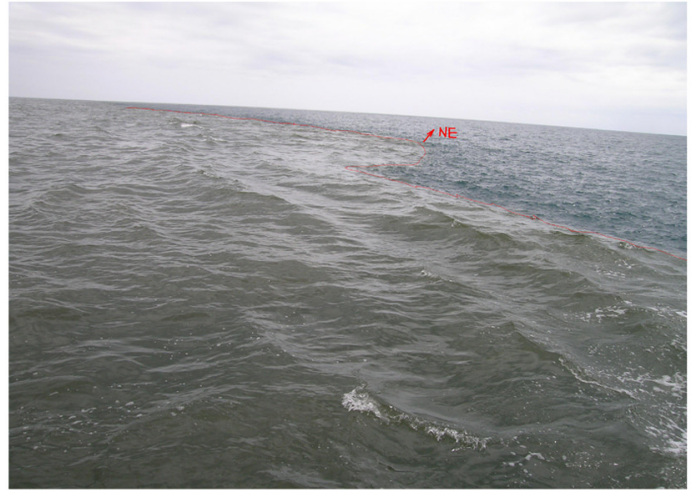

(d)

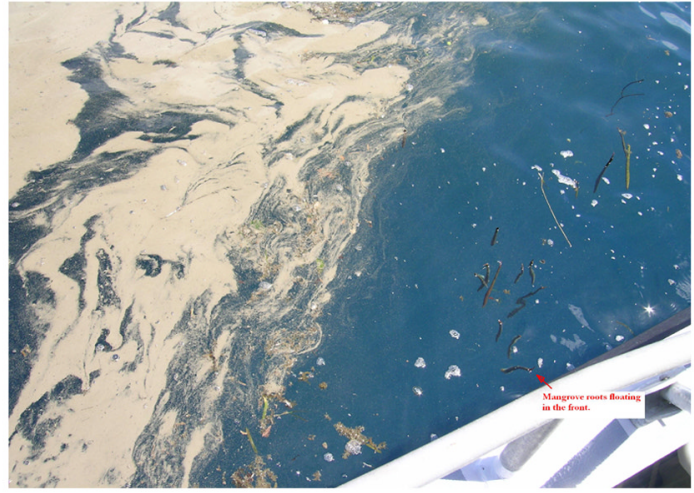

(f)

Figure 8. Frontal structures as seen from the airplane (Figure 8a), research boat (Figures $8 \mathrm{~b}$ and $8 \mathrm{~d}-8 \mathrm{f}$ ) or on the pier (Figure 8c). (a) An airscape showing the river plume and its front on 17 February 2004; (b) a S-shaped detritus line separating the same water on 17 February 2004; (c) a sharp foam line separating the same water on 16 February 2004; (d) a turbidity front with distinctly different turbidity on each side on 14 February 2004; (e) a biological front comprised of nitrogen-fixing bacteria Trichodesmium on 17 February 2004; and (f) detailed front line in Figure 8e. Mangrove roots were easily seen inside the clear water (to the right), and floating bacteria were outside the line (to the left).

suspended sediment concentration was less than 0.1 to $0.3 \mathrm{~kg} / \mathrm{m}^{3}$, free settling predominated [see Mehta, 1989].

\section{Data Interpretation}

\subsection{A Forced Plume off the Herbert River}

[31] Two important nondimensional numbers are usually used for a description of an estuary based on fluid dynamics principles: the ratio of tidal volume to fresh water volume over one tidal cycle, and the Froude number or Richardson number. An estuary number defined by Turner [1973] includes these combined effects as follows

$$
E_{S}=P_{t} F_{0}^{2} / Q_{f} T
$$


(a) Site J2
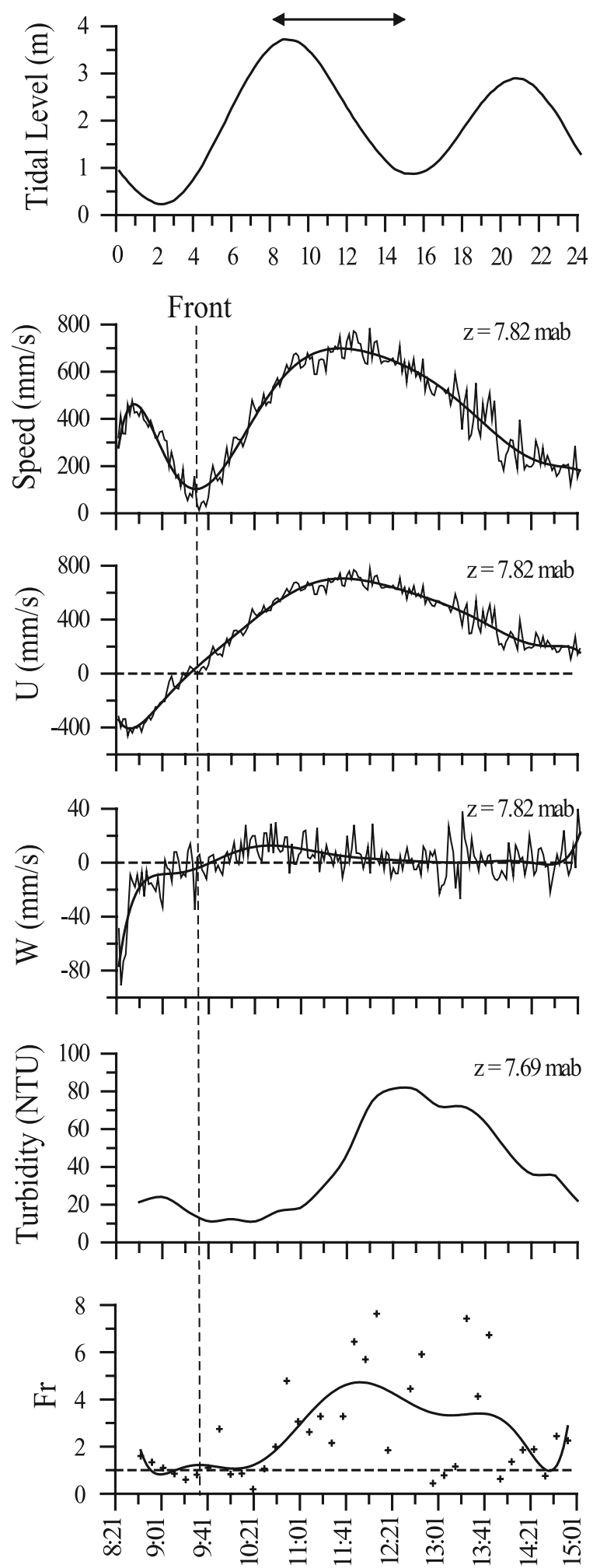

Hours on 19 February 2004 (b) Site J7
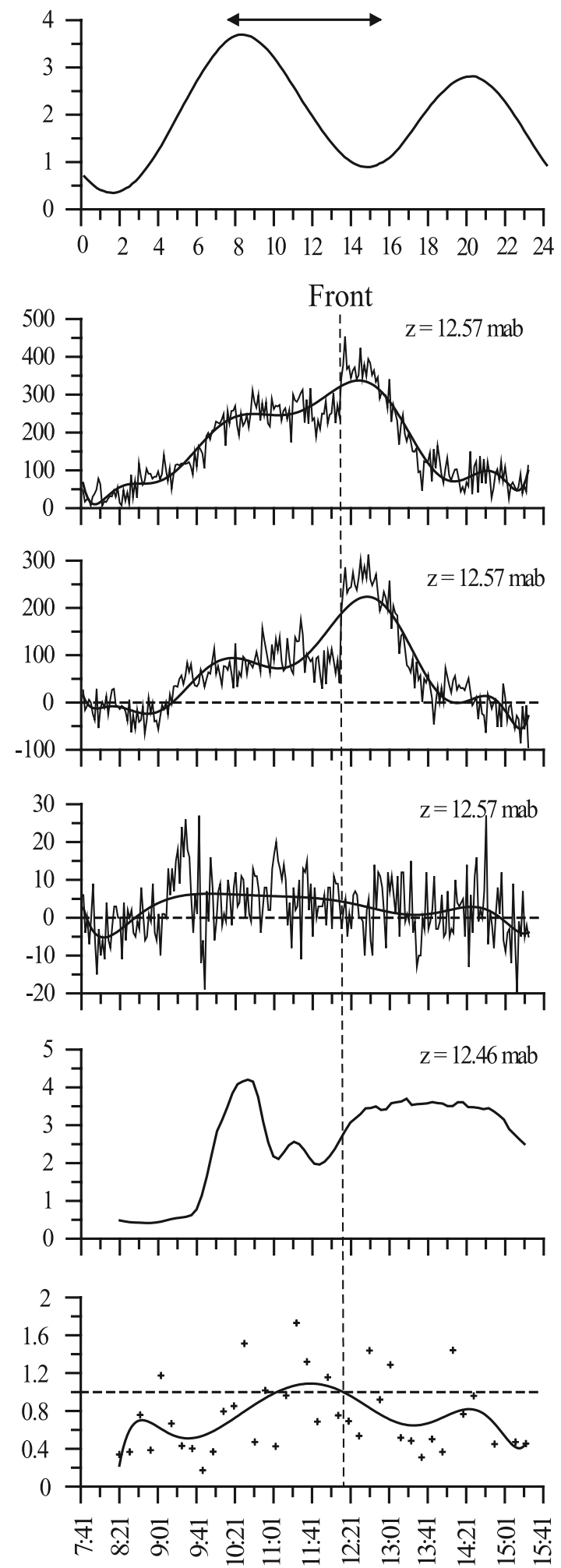

Hours on 18 February 2004

Figure 9. Time series of tidal level, flow speed, cross-shelf velocity, vertical velocity, turbidity, and internal Froude number at sites $\mathrm{J} 2$ and J7, respectively. The arrows in the tidal level indicate the surveying period for the velocity and turbidity. Thicker solid lines in the velocity panels are the smoothed low-frequency curves. Positive values indicate offshore or upward directions in the velocity components. 
Site J2
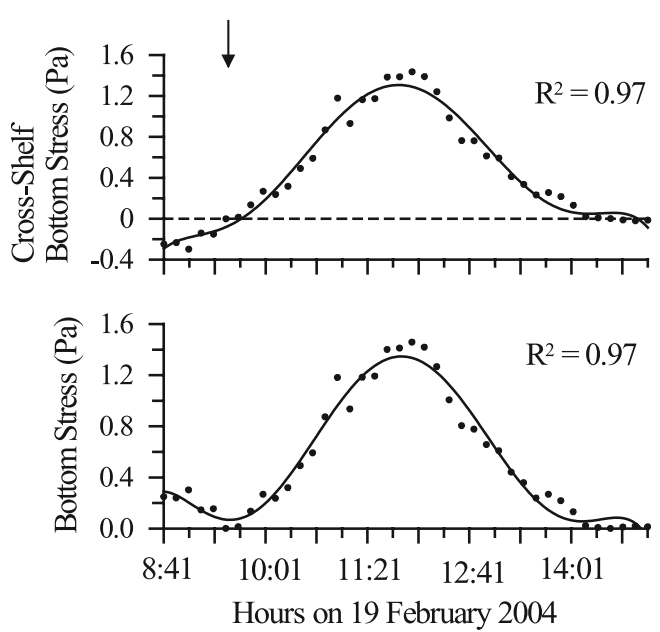

Site J7
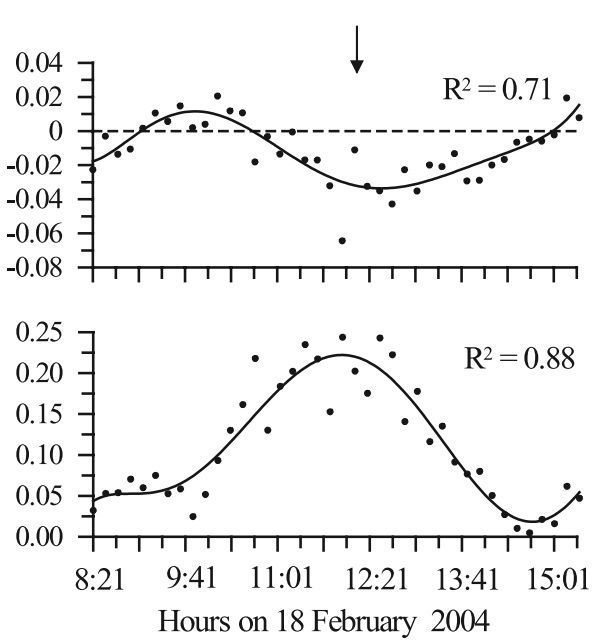

Figure 10. Time series of the cross-shelf bottom stress component $\left(\tau_{b x}\right)$ and overall bottom stress $\left(\tau_{b}\right)$ at two sites J2 and J7. Offshore stresses are positive. The vertical arrows indicate the frontal occurrence.

where $P_{t}$ is the 'tidal prism' (the volume of sea water entering the estuary on the flood tide), $P_{t}=U_{0} b h T$, where $b$ is the width of the estuary, $F_{0}=U_{0} / \sqrt{g h}$ is an ordinary Froude number based on the tidal mean velocity $U_{0}$ and the water depth $h, Q_{f}$ is the fresh water discharge and $T$ is the tidal period. Substituting into the estuary number yields

$$
E_{S}=P_{t} U_{0}^{2} / g h Q_{f} T=U_{0}^{3} b / g Q_{f}
$$

For the Herbert River estuary with $U_{0}=0.03 \mathrm{~m} / \mathrm{s}, b=2 \mathrm{~km}$, and $Q_{f}=\mathrm{O}\left(10^{0}-10^{4}\right) \mathrm{m}^{3} / \mathrm{s}, \mathrm{E}_{s}=O\left(10^{-3}-10^{-7}\right) \ll 0.03$. According to the criteria defined by Harleman and Ippen [1967], the division between stratified and well-mixed cases occurs in the range $E_{S}=0.03-0.3$, and therefore the Herbert River estuary is highly stratified.

[32] The extent to which the river plume responds to the earth's rotation depends on the Kelvin number, defined by Garvine [1987] as $K_{m}=L_{m} / L_{D}$, where $L_{m}=2 \mathrm{~km}$ is the width at the Herbert River estuary entrance, and the baroclinc Rossby radius $L_{D}=\left(g^{\prime} h_{p}\right)^{1 / 2} / f=5 \mathrm{~km}$, where $g^{\prime}=$ $g \Delta \rho / \rho$ is the reduced gravity, $h_{p}=2 \mathrm{~m}$ is the thickness of the buoyant plume, and $f=2 \Omega \sin \Phi=4.63 \times 10^{-5} \mathrm{~s}^{-1}$ is the Coriolis frequency associated with the Earth's angular velocity $\Omega$, where $\Phi$ is the latitude, $g$ is the gravity acceleration. Thus $K_{m}=0.4$, i.e., the inertial effect of the river plume is more important than the earth's rotation. An inertia-dominated river plume widely occurs in other mountainous rivers [e.g., Warrick et al., 2004], so it may be hypothesized that the inertia-dominated dispersal may be an important characteristic in the small, mountainous rivers, and the river plume is strongly influenced by river inertia, called a forced plume [List, 1982].

\subsection{Sediment Deposition and Resuspension}

[33] The total drag force may be partitioned into skin friction and form drag. The drag exerted by flow on smooth "streamlined" surface is referred to as skin friction. The form drag arises from the difference in pressure on the upstream and downstream sides of the obstacle [Nielsen, 1992]. It is the skin friction shear stress that is responsible for sediment entrainment and transport [Nielsen, 1992]. For any given value of total bed stress, the skin friction decreases as form drag increases [Wright, 1995, p. 118].

[34] The skin drag stress (Figure 10) was obtained using a quadratic drag law $\tau_{b}=\rho C_{D}\left|U_{b}\right| U_{b}$, where $C_{D}$ is the bottom drag coefficient with a typical value of $3.1 \times 10^{-3}$ for mixed sand and mud bottom conditions [Soulsby, 1990], $\left|U_{b}\right|=\sqrt{u_{b}^{2}+v_{b}^{2}}$ is the amplitude of near-bottom velocity, and $U_{b}$ is the near-bottom velocity where $u_{b}$ and $v_{b}$ represent its horizontal components. Comparison between the bottom stress (Figure 10) and the isopycnal (Figure 6) shows that the base level of the river plume is closely associated with the direction and magnitude of the crossshelf bottom stress component, rather than the overall bottom stress. An offshore bottom stress during the ebb tide would raise the level of the interface, whereas an onshore stress during the flood tide would depress the level. The larger the bottom stress component, the deeper (shallower) the interface would be in the flood (ebb) tide. Therefore the river plume became thicker in the flood tide and thinner in the ebb tide (Figure 6).

[35] For mud deposition and erosion, critical shear stresses for deposition and erosion are complex parameters to determine. According to the results by Ariathurai and Krone [1976], the critical stress for deposition may be the same or less than the critical stress for erosion. Based on laboratory experiments carried out with natural mud from the Western Scheldt, Winterwerp et al. [1991] found a critical shear stress for deposition $\tau_{c d}=0.2 \mathrm{~Pa}$. Mulder and Udink [1991] proposed a critical shear stress for erosion $\tau_{c e}=0.4 P a$. The critical shear stresses for erosion may be roughly estimated using $\tau_{c e}=0.25 d_{*}^{-0.6} \gamma_{s} d \times \operatorname{Tan} \phi$ for silts and sands [see Fischenich, 2001], where $d_{*}=d\left(g^{\prime} / v^{2}\right)^{\frac{1}{3}}, \phi$ is the angle of repose of the particle, $\gamma_{s}=g\left(\rho_{s}-\rho_{w}\right)$ is the specific weight of the grain, $g^{\prime}=\mathrm{g}(\gamma-1)$ is the reduced gravity, $\gamma=\rho_{s} / \rho_{w}, g$ is the gravitational acceleration, $\rho_{s}$ is the density of the sediment grain, $\rho_{w}$ is the density of water, $v$ is the kinematic viscosity, and $d$ is the size of the particle of bed material; a median size in the present case. An estimated critical stress is $0.16 P a$ at the site $\mathrm{J} 2(d=135 \mu \mathrm{m}$, 
$\gamma-1=132)$ and $0.11 P a$ at site $\mathrm{J} 7(d=4.69 \mu \mathrm{m}, \gamma-1=$ 1.17), which are both close to the critical stress for deposition determined by Winterwerp et al. [1991], and twofold smaller than the critical stress for erosion proposed by Mulder and Udink [1991].

[36] If the value of $0.16 \mathrm{~Pa}$ is roughly viewed as the critical stress to move the bed material off the Herbert estuary, resuspension predominated at site J2 while deposition did at site $\mathrm{J} 7$ (Figure 10). Thus, the lower nepheloid flow was caused by advection and settling from the river plume, with little by bottom material resuspension. This was distinct from the case in the dry season when a higher nepheloid layer (approximately $1 \mathrm{~kg} / \mathrm{m}^{3}$ ) resuspended by wind waves was found to extend about $30 \mathrm{~km}$ offshore [Wolanski and Spagnol, 2000; Wolanski et al., 2003]. There was no occurrence of intense stratification when river runoff was negligible, and the bottom stress induced by wind waves could be significantly enhanced in the shallow waters, resulting in intense resuspension. Therefore, offshore spreading and settling in the surface nepheloid layer would predominate in wet season in the presence of intense stratification, while offshore spreading in the lower nepheloid layer induced by resuspension occurred in the dry season in the absence of intense stratification.

\section{Theoretical Analyses}

[37] The amount of field information collected is in a way presenting a snapshot of the river plume and sediment dispersal. The length of the time series and the number of transects is in fact rather limited to study the three dimensional behavior of a forced plume. So theoretical analyses were carried out to in-depth understand the processes controlling the suspended sediment dispersal pattern and its fate in the stratified flow. Section 6.1 concentrates on the occurrence of internal hydraulic jump using the TaylorGoldstein equation in the absence of shear effect, section 6.2 focuses on the hydraulic control which determines the shape of the river plume, and mechanical energy loss associated with the internal hydraulic jump, and in section 6.3 , a simple mass conservation equation is used to discuss the cross-shelf (or along-plume) fate of sediment dispersal by the river plume.

\subsection{Internal Hydraulic Jump}

[38] The stability and evolution of a stratified shear flow may be examined using the Taylor-Goldstein (TG) equation. Hydrostatic pressure and Boussinesq approximation are assumed, and viscosity and diffusivity are neglected. Under the assumptions that (a) the buoyancy frequency $N^{2}=-(g / \rho)(\partial \rho / \partial z)$ is a constant, where $\rho=\bar{\rho} \exp (-a z)$ is assumed to be the density in the absence of internal waves, (b) a free surface is assumed, (c) the geostrophic effect is negligible on the small scale, the TG equation was used to examine small-amplitude, long-wavelength disturbances in the stratified medium [see Drazin and Reid, 1981]. We represent perturbations to the background velocity (horizontal and vertical components), density and pressure fields by $(u, w), \rho$ and $p$, respectively. Consider an internal wave with an angular frequency $\omega$ and a horizontal wave number $k$, and the vertical velocity is expressed as $w=W(z) \exp [i(\omega t-k x)]$. Since the flow velocity is much smaller than the long-wave phase velocity, the TG equation in a two-dimension stratified flow in the absence of the shear effect is expressed as

$$
\frac{d^{2} W}{d z^{2}}+\left(\frac{N^{2}}{c^{2}}-k^{2}\right) W=0
$$

where $c$ is the horizontal phase velocity, satisfying $c=\omega / k$.

[39] Defining a stream function $\psi=\hat{\psi}(z) \exp [i(\omega t-k x)]$ that satisfies $u=\partial \psi / \partial z$ and $w=-\partial \psi / \partial x$ based on the continuity equation $\partial u / \partial x+\partial w / \partial z=0$, so the amplitude of the vertical velocity is rewritten as $W=i k \hat{\psi}$, and substituting into the TG equation yields

$$
\frac{d^{2} \hat{\psi}}{d z^{2}}+\left(\frac{N^{2}}{c^{2}}-k^{2}\right) \hat{\psi}=0
$$

Equation (4) has the general form of solution for the case of $N>\omega$,

$$
\hat{\psi}=A_{2} \exp \left[i k\left(\frac{N^{2}}{\omega^{2}}-1\right)^{\frac{1}{2}} z\right]+B_{2} \exp \left[-i k\left(\frac{N^{2}}{\omega^{2}}-1\right)^{\frac{1}{2}} z\right] .
$$

So the vertical velocity is expressed as

$$
\begin{aligned}
w= & i k\left\{A_{2} \exp \left[i k\left(\frac{N^{2}}{\omega^{2}}-1\right)^{\frac{1}{2}} z\right]+B_{2} \exp \left[-i k\left(\frac{N^{2}}{\omega^{2}}-1\right)^{\frac{1}{2}} z\right]\right\} \\
& \cdot \exp [i(\omega t-k x)] .
\end{aligned}
$$

Assuming the sea surface and bed boundary conditions, $\left.w\right|_{z=0}=0$ and $\left.w\right|_{\mathrm{z}=-\mathrm{h}}=0$, respectively, and substituting into equation (6) yields the dispersion relation

$$
\omega^{2}=\frac{N^{2} k^{2} h^{2}}{n^{2} \pi^{2}+k^{2} h^{2}}, \text { where } n=1,2,3 \cdots \cdots
$$

So the eigenfunction of the vertical velocity may be given for the specific eigenvalue

$$
w=A \sin \left(\frac{n \pi}{h} z\right) \exp [i(\omega t-k x)], n=1,2,3 \cdots \cdots
$$

where $A=2 A_{2} k$, and $A_{2}$ is the maximal vertical displacement at the stratified interface.

[40] Now we define the wave number in equation (8), $m^{2}=l^{2}+k^{2}$, where $l=n \pi / h=\left(N^{2} / c^{2}-k^{2}\right)^{\frac{1}{2}}$ is the vertical wave number. The phase velocity may be obtained from the dispersion relation

$$
c^{2}=\frac{\omega^{2}}{k^{2}}=\frac{N^{2}}{m^{2}} \text {. }
$$

The horizontal velocity may also be derived from the stream function for the given eigenvalue,

$$
u=\hat{u}(z) \sin (\omega t-k x)=2 A_{2} l \cos (l z) \sin (\omega t-k x) .
$$

So for the mode- 1 structure $(n=1)$ in a long wave $(k h \ll 1)$, the internal Froude number reads

$$
F r=\frac{\hat{u}}{c}=\frac{2 A_{2} \pi^{2}}{N h^{2}} \cos \left(\pi \frac{z}{h}\right)
$$




\section{(a) During ebb tide}

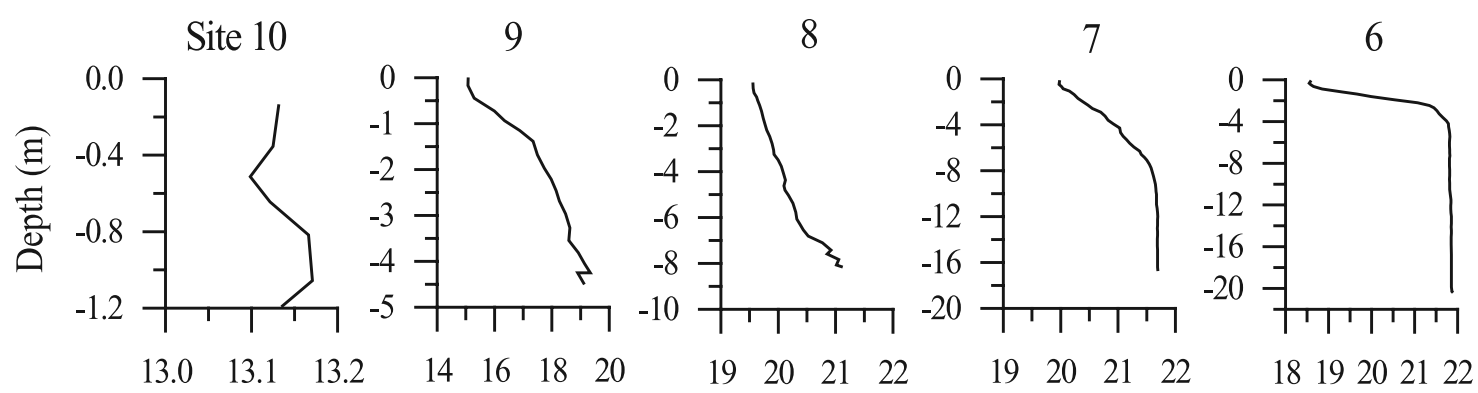

Density $\left(\mathrm{kg} / \mathrm{m}^{3}\right)$
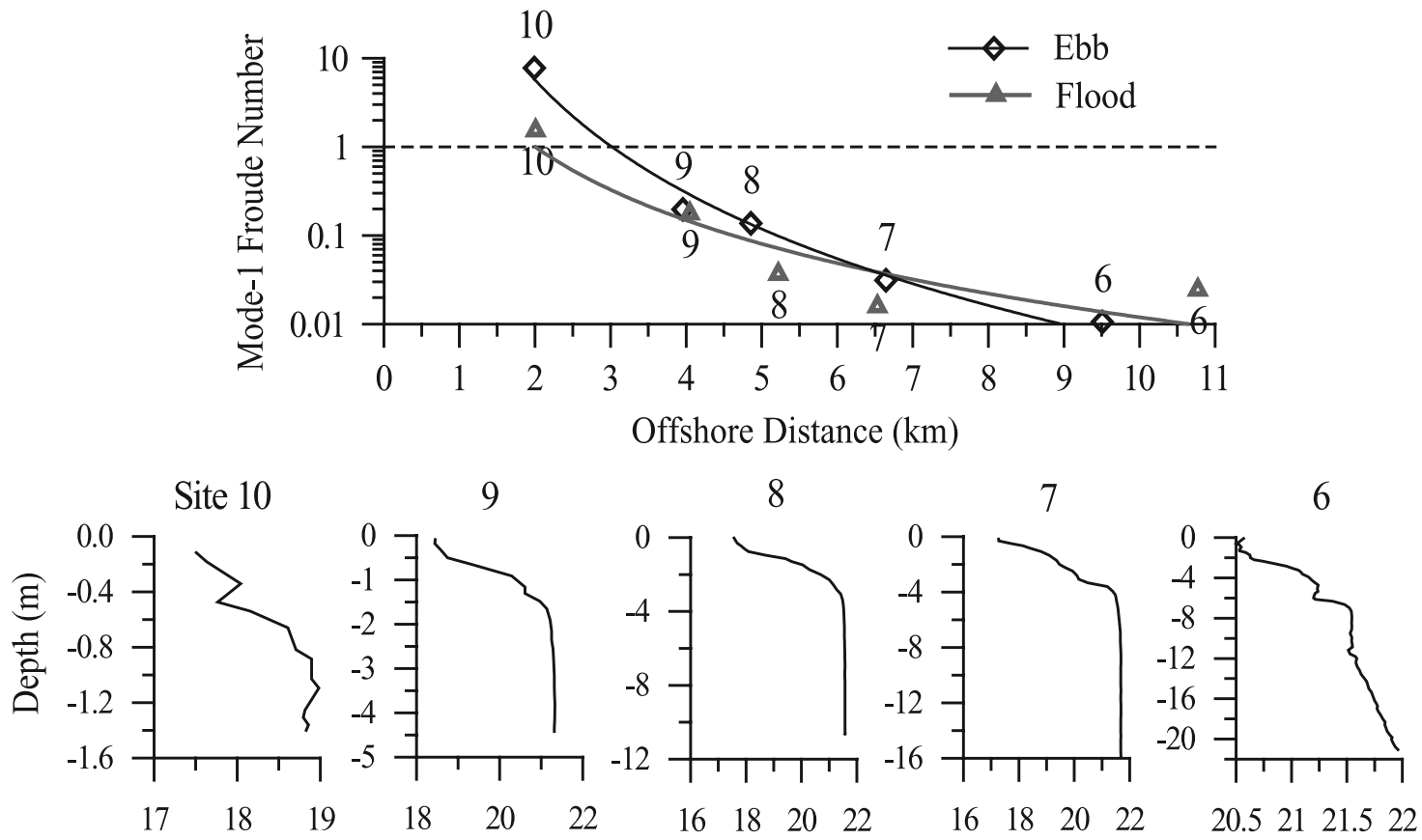

Density $\left(\mathrm{kg} / \mathrm{m}^{3}\right)$

\section{(b) During flood tide}

Figure 11. The mode-1 internal Froude number (Fr) versus the across-shelf distance along the north transect during (a) the ebb period on 20 February and (b) the flood period on 19 February. An abrupt transition from $\mathrm{Fr}>1$ to $F r<1$ occurs only in the ebb period. Density profiles are also shown for reference.

Equation (11) shows that the internal Froude number varies monotonously with the water depth, being a positive value in the upper layer and negative in the lower layer, and zero at middepth. Within the stratified layer, a subcritical flow must exist at middepth, while a supercritical flow may exist in the upper and lower layers, respectively. These characteristics may be clearly seen from the inversed Richardson number distribution at the site $\mathrm{J} 7$ in Figure 6. On the Herbert inner shelf, the across-shelf water depth may be simply generalized as $h(x)=s x$, where $s$ is the cross-shelf slope relative to a horizontal level. Thus, equation (11) indicates quantitatively that the internal Froude number has an inverse squared relation with the cross-shelf distance, and therefore the flow is certain to pass from supercritical to subcritical, through an internal hydraulic jump at the critical point $(F r=1)$. Actual estimates along the north transect indicate that the internal hydraulic jump occurred more frequently in the ebb tide than in the flood tide (Figure 11). As discussed at the beginning of section 5.1, the Froude number is an important nondimensional number used for a classification scheme for estuaries. It is rather advisable that the along-plume variation of the Froude number may be used to classify the river plumes in the presence or absence of an internal hydraulic jump.

\subsection{Hydraulic Control}

[41] Internal hydraulic theory can be used to describe density-driven flows in which fluid motion is determined by the balance between a buoyancy force and an inertia force. Stratified hydraulic flow as a two-layer system with the hydrostatic approximation has been widely studied and compared with theory [see Baines, 1984; Armi, 1986; Lawrence, 1993; Nash and Moum, 2001]. The key to understanding hydraulic flows lies in the existence of 


\section{Offshore Distance (m)}
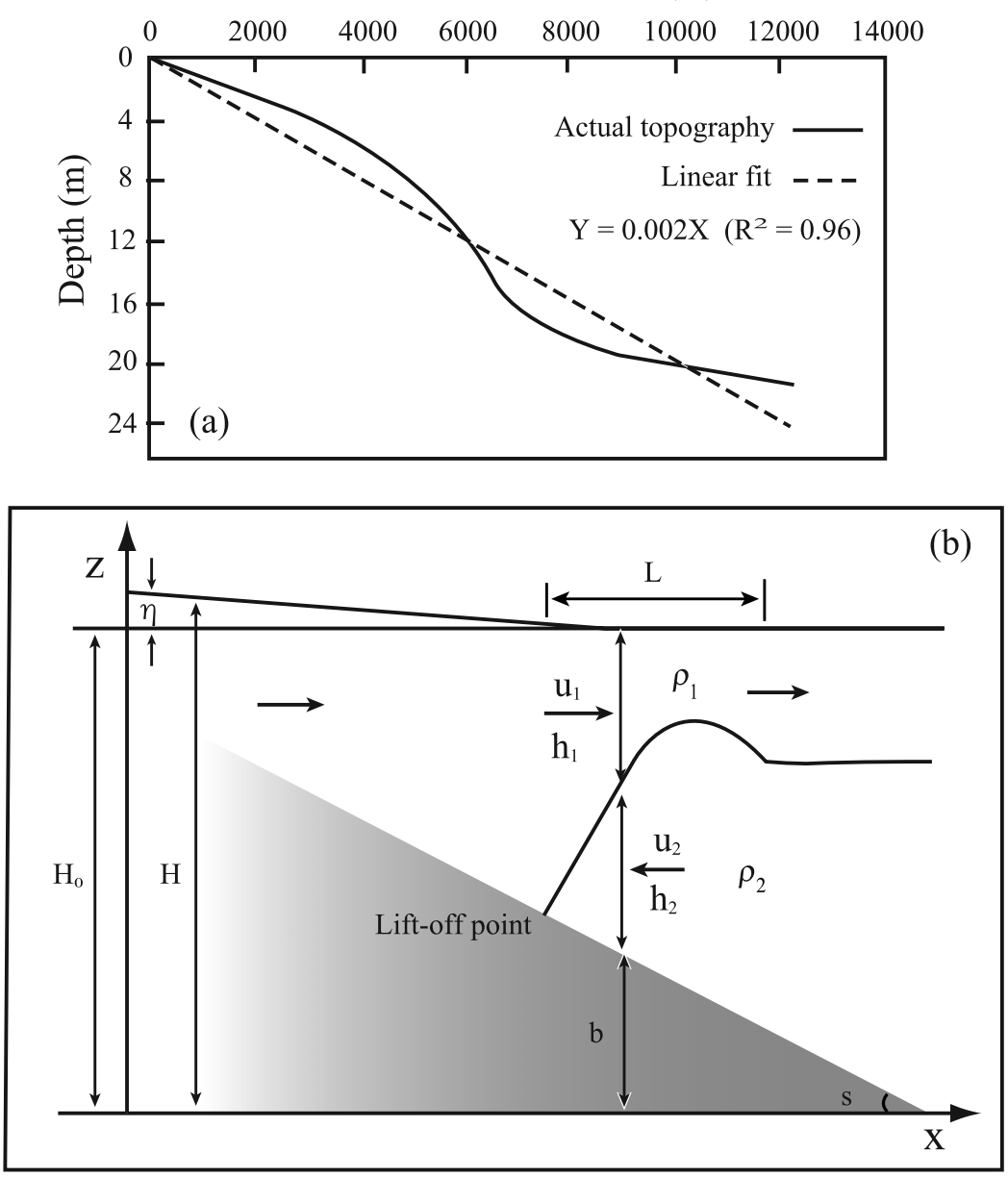

Figure 12. The topographical profile along the north transect (a), and the notation used to describe the motion of the stratified flow within the jump section (b). $L$ indicates the jump length. Other symbols are explained in the text.

control points. In this section, a two-layer hydraulic theory is used to determine the river plume geometry and hydraulic jump energy losses for the cases consistent with the observations.

[42] To evaluate and quantify the influence of hydraulic control, we consider a two-layer stratified flow over a gentle slope (Figure 12a). A schematic of the flow is given in Figure $12 \mathrm{~b}$, based on the flow and density observations. The specific mechanical energy of each layer can be written in terms of the Bernoulli equations:

$$
\begin{gathered}
E_{1}=\rho_{1} g H+\rho_{1} u_{1}^{2} / 2, \\
E_{2}=\rho_{1} g H+\Delta \rho g\left(h_{2}+b\right)+\rho_{2} u_{2}^{2} / 2,
\end{gathered}
$$

where $\rho_{i}, h_{i}$ and $u_{i}$ are density, sublayer thickness and horizontal velocity in each layer (subscript $i=1,2$ indicates the upper and lower layer, respectively), $b$ is the subaqueous topography relative to a prescribed local datum, $H=h_{1}+$ $h_{2}+b$ is total depth relative to the datum, $\Delta \rho=\rho_{2}-\rho_{1}$ is the density difference between two layers, $g$ is the gravitational acceleration. Differentiating the equations with respect to $x$ and equating the energy loss within each layer $\left(d E_{i} / d x, i=1\right.$ and 2$)$ to shear stress divergence across it, the matrix equation governing the flows is

$$
\begin{aligned}
& \left(\begin{array}{cc}
\rho_{1}\left(1-F r_{1}^{2}\right) & \rho_{1} \\
\rho_{1} & \rho_{2}\left(1-F r_{2}^{2}\right)
\end{array}\right)\left(\begin{array}{l}
\frac{d h_{1}}{d x} \\
\frac{d\left(h_{2}+b\right)}{d x}
\end{array}\right) \\
& =\left(\begin{array}{cc}
\frac{\tau_{0}-\tau}{g h_{1}} \\
-\rho_{2} F r_{2}^{2} \frac{d b}{d x}+\frac{\tau-\tau_{b}}{g h_{2}}
\end{array}\right),
\end{aligned}
$$

where $\tau_{0}, \tau$ and $\tau_{\mathrm{b}}$ indicate shear stresses at the surface, intermediate interface and at the bottom, respectively. The internal Froude number is defined as $F r_{i}^{2}=q_{i}^{2} / g^{\prime} h_{i}^{3}$, where $q_{i}=h_{i} u_{i}$ is the flow volume transport rate per unit width in each layer (subscript $i=1,2), g^{\prime}=g \Delta \rho / \rho$ is the reduced gravitational acceleration. 
[43] For convenience, we define a hydraulic Froude number based on shear stresses between the two interfaces in each layer,

$$
F_{i}^{2}=\frac{\tau_{i}}{\rho_{i} g h_{i}}=\frac{u_{i}^{2}}{g h_{i}}
$$

where $\tau_{i}=\rho_{i} u_{i^{*}}^{2}$ is the resultant shear stress in each layer (the subscript $i=1,2$, e.g., $\tau_{1}=\tau_{0}-\tau$ in the upper layer, and $\tau_{2}=\tau-\tau_{b}$ in the lower layer), and $u_{i^{*}}$ denotes corresponding frictional velocity.

[44] A composite Froude number for the two-layer stratified flow is defined as

$$
G^{2}=F r_{1}^{2}+F r_{2}^{2}-F r_{1}^{2} F r_{2}^{2}+r
$$

where the relative density is $r=\rho_{1} / \rho_{2}$. By analogy with the open channel flow, the composite Froude number indicates the regime of stratified flow. The flow is subcritical when the composite Froude number is smaller than unity, and is supercritical when it is greater than unity, and in a critical regime at unity. An internal hydraulic jump occurs when the flow changes from supercritical to subcritical regime.

[45] Assuming that the surface water level $\eta$ is primarily controlled by the tide, neglecting the set-up induced by wind waves (or internal waves), the horizontal gradient of the whole depth $\left(H=H_{0}+\eta\right)$ is equal to the tide level gradient

$$
\frac{d H}{d x}=\frac{d\left(H_{0}+\eta\right)}{d x}=\frac{d \eta}{d x}
$$

where $H_{0}$ is the equilibrium depth of the free surface relative to the prescribed local datum, $\eta(x, t)=A_{0} \cos \left(\omega_{0} t+k_{0} x\right)$ is the surface elevation relative to its equilibrium position, where $A_{0}, \omega_{0}$ and $k_{0}$ are the amplitude, angular frequency and wave number of the surface wave, respectively. The former two parameters can be obtained from the tide harmonic analyses.

[46] The subaqueous topography across-shelf off the Herbert River mouth may be generalized as $b(x)=H_{0}-s x$ (Figure 12b). If the equilibrium depth of the free surface $H_{0}=0$, then $b(x)=-s x=-h(\mathrm{x})$, where $h(x)$ is the water depth defined in the above section. The horizontal gradient of the slope may further be expressed as $d b / d x=-s$.

[47] Neglecting the surface and intermediate shear stresses, i.e., $F_{1}^{2}=0$, and when $G^{2} \neq 1$, the matrix equation (14) yields,

$$
\begin{gathered}
\frac{d h_{1}}{d x}=-\frac{1}{1-G^{2}}\left(F r_{2}^{2} s+F_{2}^{2}\right), \\
\frac{d\left(h_{2}+b\right)}{d x}=\frac{1}{1-G^{2}}\left[\left(1-F r_{1}^{2}\right)\left(F r_{2}^{2} s+F_{2}^{2}\right)\right], \\
\frac{d \eta}{d x}=-\frac{1}{1-G^{2}}\left[F r_{1}^{2}\left(F r_{2}^{2} s+F_{2}^{2}\right)\right] .
\end{gathered}
$$

These are the simplified equations controlling the interfacial geometry of the stratified flow. In the following text, we will examine the interface shape of the river plume in the absence and presence of an internal hydraulic jump, respectively.

\subsubsection{Normal Interface Geometry in the Two-Layer Stratified Flow}

[48] Substituting Equation (18) into Equation (20) yields

$$
\frac{d \eta}{d x}=F r_{1}^{2} \frac{d h_{1}}{d x}
$$

The solution of equation (21) yields the thickness of the upper layer

$$
h_{1}=\left(-\frac{q_{1}^{2}}{2 g^{\prime} \eta}\right)^{\frac{1}{2}}=\left[-\frac{q_{1}^{2}}{2 g^{\prime} A_{0}} \sec \left(\omega_{0} t+k_{0} x\right)\right]^{\frac{1}{2}} .
$$

If the thickness of the upper layer is determined, the interface between the upper and lower layers relative to the local datum is determined by $h_{2}+b=H_{0}+\eta-h_{1}$. Equation (22) indicates that the stratified interface is controlled by the inflow rate, the reduced gravity and the surface water level, irrespective of the bottom stress. For fixed values of the inflow rate and the reduced gravity, the stratified interface is characterized only by the negative part of a secant function, which looks sound from the isopycnals during the ebb tide in Figure 5. When the maximum value of the secant function is adopted, i.e., $\sec \left(\omega_{0} t+k_{0} x\right)=-1$, the thickness at the control point may be derived as

$$
h_{1 \min }=\left(\frac{q_{1}^{2}}{2 g^{\prime} A_{0}}\right)^{\frac{1}{2}}
$$

\subsubsection{Critical Interface in the Two-Layer Stratified Flow}

[49] For a two-layer stratified flow the composite Froude number defines whether the flow is critical $\left(G^{2}=1\right)$ with respect to the first internal mode [Armi, 1986]. The local maxima and minima in the plot of lower-layer energy versus the interface height occur where $G^{2}=1$ [Farmer and Denton, 1985]. Equations (18)-(20) indicate that when $G^{2}=1$ and $F_{1}^{2} \neq 1$, the following condition must be satisfied,

$$
F r_{2}^{2} s+F_{2}^{2}=0
$$

Solution of equation (24) yields the critical thickness in the lower layer

$$
h_{2 c}=\left[-\frac{\rho_{1} q_{2}^{2} s}{(1-r) \tau_{b}}\right]^{\frac{1}{2}}
$$

This expression indicates that $\tau_{b}<0$ is always required when the flow is at the critical regime, and the thickness of the lower layer is inversely proportional to the squared root of the bottom stress. This finding may be used to understand the tidal responses of the pycnoclines at the site $\mathrm{J} 7$ in Figure 6. The larger the bottom stress component (Figure 10), the thicker the lower layer would be in the ebb tide (Figure 6). Estimates of the critical thickness of the lower layer at site J7 show a better agreement in oscillation and its amplitude 


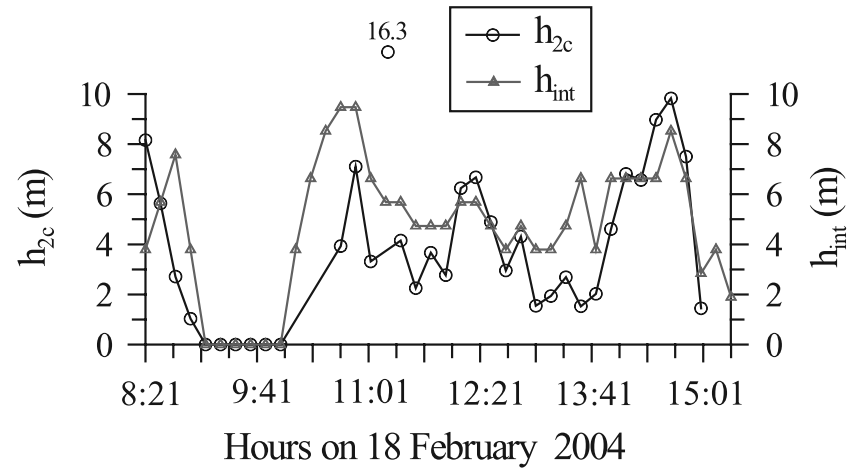

Figure 13. Comparison between the critical thickness in the lower layer $\left(h_{2 c}\right)$ and the interface elevation of the stratified flow $\left(h_{i n t}\right)$. The zero value of the thickness or elevation indicates the case during the flood tide, when the critical thickness can not be solved from its expression.

with the interface elevation of the stratified flow (Figure 13). Theoretically, if $\tau_{b} \rightarrow \infty$, then $h_{2 c} \rightarrow 0$, i.e., the lift-off point where the upper plume layer is detached from the bed is at a singular point of the cross-shelf distribution of the bottom stress. In practice it cannot occur that the bottom stress $\tau_{b}$ tends to infinite, but the stress probably increases sufficiently at the lift-off point. The drag force may be partitioned into skin friction and form drag, i.e., $\tau_{b}=\tau_{b b l}+$ $\tau_{\text {form }}$. The stress associated with form drag over the hydraulically active section of the slope $\Delta x$ is expressed as $\tau_{\text {form }}=F_{\text {form }} / \Delta x$, where the drag force per unit width is determined by $F_{f o r m}=-\int_{\Delta x} p(b) \frac{d b}{d x} d x$, with endpoints of integration occurring at equal depths [Baines, 1996]. Assuming a hydrostatic pressure $p(b)=\int_{b}^{H} \rho g d z$, the form drag stress may be expressed as $\tau_{\text {form }}=\frac{1}{\Delta x} \int_{\Delta x} \int_{b}^{H}(\rho g s) d z d x$. This expression indicates that the bottom stress due to form drag increases directly with the product of the fluid density and the across-shelf topographic slope, and thus the possible maximum stress should occur at the toe of underlying highsalinity water intrusion or near the inflection point of the bed slope. That is the mechanism for the river plume detachment from bed at the lift-off point, as needs to be further verified via field observations.

[50] Substituting equation (25) into $G^{2}=1$ yields the critical thickness in the upper layer

$$
h_{1 c}=\left[\frac{q_{1}^{2}\left(1-F r_{2 c}^{2}\right)}{g^{\prime}\left(1-F r_{2 c}^{2}-r\right)}\right]^{\frac{1}{3}},
$$

where $F r_{2 c}^{2}=q_{2}^{2} / g^{\prime} h_{2 c}^{3}$. If $q_{2}=0$, then $F r_{2 c}^{2}=0$ and $h_{2 c}=0$ derived from equation (25), the critical thickness of the upper layer at the lift-off point is associated with the inflow rate and the reduced gravity, irrespective of the bottom stress,

$$
h_{1 c}=\left[\frac{q_{1}^{2}}{g^{\prime}(1-r)}\right]^{\frac{1}{3}} \text {. }
$$

\subsubsection{Mechanical Energy Loss Within the Internal Hydraulic Jump}

[51] The net energy flux into the jump is the difference between the energy flux into and out of it. Assuming the mass conservation in the upper layer for $q_{2}=0$, the mechanical energy loss per unit width between two sections at the lift-off point and the end of the jump, respectively, gives

$$
\Delta E=B\left[1+\frac{1}{2} F r_{1}^{2} \beta(\beta+1)\right],
$$

where $B=\rho_{1} g^{\prime}\left(h_{1 n}-h_{1 c}\right)$ may be considered as the potential energy driven by the buoyancy, $\beta=h_{1 c} / h_{1 n}$ is defined as the conjugate depth ratio before and after the jump, and $F r_{1}$ is the internal Froude number at the lift-off point. Substituting equation (26b) into equation (27a) yields

$$
\Delta E=B\left[1+\frac{1}{2} \beta(\beta+1)(1-r)\right] .
$$

Since the value of $1-r$ is usually on an order of $10^{-3}$, the second term in the bracket may be ignored, i.e., $\Delta E \approx B=$ $\rho_{1} g^{\prime}\left(h_{1 n}-h_{1 c}\right)$. So the mechanical energy loss within the internal hydraulic jump is controlled by the reduced gravity and the jump height, defined as the difference of water depths before and after the jump. Majority of the energy loss within the jump section is transferred to the buoyancydriven potential energy, uplifting the bottom interface of the river plume. In a steady state, the net energy flux into the jump must be balanced by dissipation. The rate of energy dissipation is composed of two parts: energy dissipation within the bottom boundary layer (BBL), and turbulent dissipation and mixing within the jump [see Moum, 1996; Nash and Moum, 2001]. The energy dissipation within BBL may be represented by $\int_{L} \tau_{b b l} u_{2} d x$, where $L$ is the length of the internal hydraulic jump on the inclined slope, or briefly, the jump length, $u_{2}$ is the velocity in the lower layer. The turbulent dissipation and mixing within the jump is indicated by $\int_{L} 1.2 \tau u_{1} d x$, where $\tau$ is the shear stress within the jump, $u_{1}$ is the velocity in the upper layer. We did not account for the energy dissipation in the above discussion, since we assumed $\tau=0$ and $q_{2}=0$ or $u_{2}=0$ for simplification. Field measurements of these energy losses and estimates of energy balance should be done in the future.

[52] Theoretical analyses of the stratified flow in the river plume showed that an internal hydraulic jump indeed occurred in the ebb tide when the river plume entered the coastal water, and majority of the energy loss within the jump section was transferred to uplift the river plume and to enhance the mixing. These processes surely retain the suspended sediments within the river plume. In this case, the along-plume sediment dispersal may take on a separative pattern (see the ebb tide sections in Figure 5). The next question is how far the nepheloid flow spreads to the offshore.

\subsection{Sediment Balance for Cross-Shelf Dispersal by River Plume}

[53] For the highly-stratified and advection-dominated river plume, the sediment balance is assumed to be between 
longitudinal advection and vertical convection. Under the assumptions that (a) the river plume has constant thickness and vertically uniform velocity and density, (b) suspended sediment is released from the river plume only by settling, and little by resuspension from the bottom in the presence of intense stratification, and (c) the along-shelf transport is not included, the along-plume (or across-shelf) distribution of the plume TSS versus the offshore distance can be derived from a one-dimensional mass balance equation

$$
\frac{\partial C}{\partial t}+U \frac{\partial C}{\partial x}=-\frac{\varpi C}{h_{1}},
$$

where $C$ is the outflow TSS, and $U$ the outflow velocity, both averaged over the river plume thickness $h_{1}$, and $\varpi$ is the bulk effective settling velocity, which is required to explain sinking losses from the river flood plume. The relative constancy of the effective settling velocity despite widely varying winds, waves, and currents is only associated with the growth rate of flocs which is a function of concentration [Hill et al., 2000; Curran et al., 2002]. Relatively low concentrations in the Herbert River plume are assumed to preclude significant increases in floc size with depth. Therefore, in the next discussions we ignore the effects of the settling velocity and flocculation on the sediment dispersal in the river plume.

[54] For a steady condition when the TSS does not change with time for fine-grained sediments, equation (28) reduces to

$$
U \frac{\partial C}{\partial x}=-\frac{\varpi C}{h_{1}}
$$

The solution of equation (29) yields an exponential decay of the TSS versus the offshore distance

$$
C=C_{0} \exp \left(-\frac{\varpi}{U h_{1}} x\right)+D_{0}
$$

where $C_{0}$ is the concentration at the river mouth, $D_{0}$ is a constant arbitrarily set to zero. The parameter $\varpi / U h_{1}=\varpi / q_{1}$ may be defined as an effective coefficient of along-plume sediment dispersal. The effective dispersal coefficient has the dimension of an inverse length [1/L] and represents a decaying rate of advection dispersal. On the other hand, the (eddy or molecular) diffusion coefficient has the dimension of length squared divided by time $\left[\mathrm{L}^{2} / \mathrm{T}\right]$ and represents the mixing conditions. Apparently these two coefficients are quite different in physics.

[55] Equation (30) indicates that the along-plume sediment spread is surely finite for a given outflow discharge $q_{1}$ and a constant bulk settling velocity. The exponential decay function is able to represent the limited distance of plume sediment spread extremely well under settling and deposition-dominated setting (Figure 14). However, under the role of lateral spreading (or along-shore transport) which causes a decrease in volume flux with seaward distance, the observed TSS values between $4-8 \mathrm{~km}$ offshore are smaller than those derived from the exponential decay law (Figure 14a), but this influence produces less than $50 \%$ bias to the predicted values (Figure 14b). The settling velocity may be
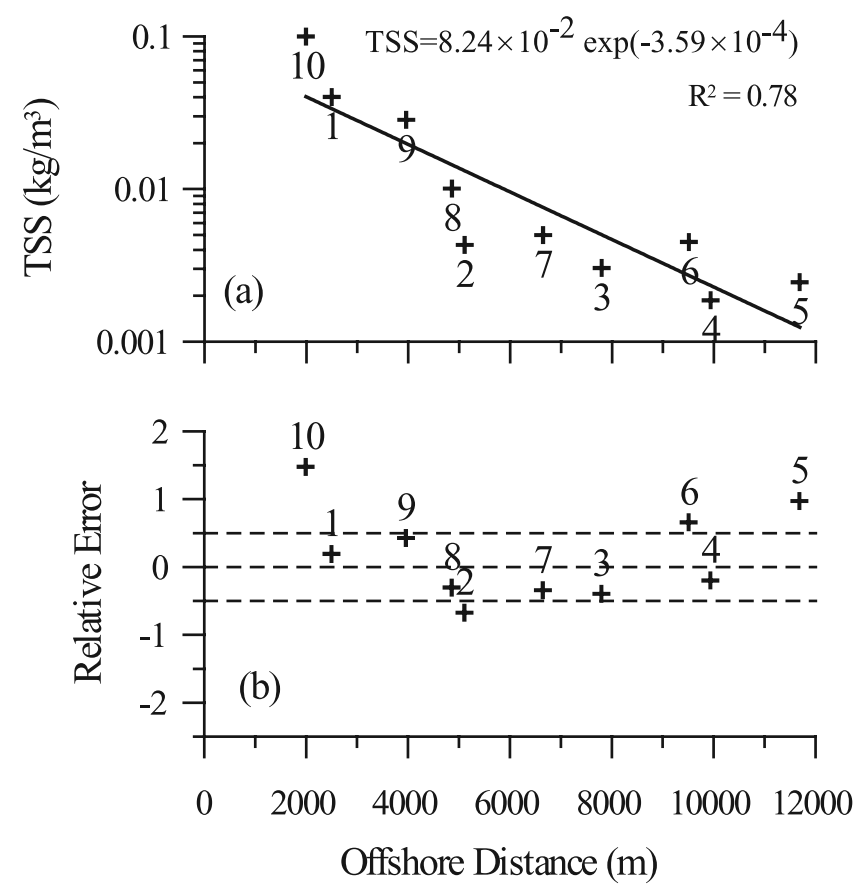

Figure 14. Cross-shelf distribution of total suspended sediment concentrations (TSS) at surface (a) and their relative errors to the exponential decay values (b) along two transects during the ebb tide on 20 February 2004. Zero meter is referenced to the point at the coast. The TSS distribution is well fitted by an exponential decay function (solid line) within a $\pm 50 \%$ limit.

another factor for the discrepancy from the model. The observed TSS values at the offshore sites 5 and 6 are larger than the predicted values, because the settling velocity at the offshore sites may be smaller than the effective settling velocity we estimated. The observed TSS value at site 10 is approximately 1.5 times larger than the predicted value due to the intense resuspension over the shallow mud bank.

[56] The exponential decay law of the TSS versus the distance was also found at a monsoon-dominated coastal environment off the Solo river in East Java, Indonesia [Hoekstra, 1989]. Walsh and Nittrouer [2003] proposed a spectrum of off-shelf transport behavior for river-sediment dispersal systems, and an exponential relationship between shelf width and percentage of off-shelf accumulation. If the exponential distribution versus offshore distance is quite suitable for both the sediment dispersal by river plumes and the off-shelf sediment accumulation, it may be inferred on the first order that sediment accumulation on the shelf is controlled principally by settling and deposition from the river plume, although the near-bottom gravity-driven flow under wave-induced resuspension [Geyer et al., 2000; Traykovski et al., 2000] may be a secondary important mechanism for cross-shelf sediment transport.

[57] For the Herbert River plume, the plume thickness was observed to be $h_{1}=2 m$ (in the ebb tide in Figure 5a), the outflow velocity $U=0.1-0.2 \mathrm{~m} / \mathrm{s}$ (at the site $\mathrm{J} 7$ in Figure 6). The effective dispersal coefficient is determined as $\varpi / U h_{1}=$ $3.59 \times 10^{-4} \mathrm{~m}^{-1}$, based on the fitted curve shown in Figure $14 \mathrm{a}$, and thus the bulk effective settling velocity $\varpi=0.07-$ 
$0.14 \mathrm{~mm} / \mathrm{s}$. This value is on the same order of $0.1 \mathrm{~mm} / \mathrm{s}$ in the Eel River flood plume estimated by Hill et al. [2000]. A typical value $1.4 \mathrm{~mm} / \mathrm{s}$ of the Stokes terminal settling velocity was estimated by $\varpi_{s}=g^{\prime} d^{2} / 18 v$, where $g^{\prime}=g(\gamma-1)$, the specific weight $\gamma-1=1.17, g$ is the gravitational acceleration, the median size of suspension particles $\mathrm{d}=0.05 \mathrm{~mm}, v$ is the kinematic viscosity of water on the order $10^{-6} \mathrm{~m}^{2} / \mathrm{s}$. Therefore, the Stokes terminal settling velocity is one order greater than the bulk effective settling velocity, indicating that free settling is much hindered by the buoyancy in the presence of intense stratification.

[58] Equation (30) may be used to determine a characteristic distance of sediment expansion in the surface nepheloid layer $\left(x_{p}\right)$, when the TSS at the offshore end $\left(C_{p}\right)$ is much smaller than the source TSS $\left(C_{0}\right)$. The offshore spread distance is derived as

$$
x_{p}=-\frac{U h_{1}}{\varpi} \operatorname{In}\left(\frac{C_{p}}{C_{0}}\right) .
$$

If the plume thickness and the bulk effective settling velocity are considered as constants, the dispersal distance is linearly controlled by the mean along-plume velocity. If the offshore TSS is assumed to decrease to $1 \%$ of the source $\mathrm{TSS}$, then the offshore spreading distance is

$$
x_{p}=4.6 \frac{U h_{1}}{\varpi} .
$$

The spread distance for the north transect in the ebb tide was estimated to be $x_{p}=12.8 \mathrm{~km}$, which is close to the distance of $10.5 \mathrm{~km}$ for the 5 -NTU constant turbidity line (the third panel in Figure 5).

\section{Conclusions}

[59] During a moderate flood event induced by Cyclone Fritz in the mountainous Herbert River estuary, field measurements were conducted at two contrasting sites and along two shore-normal transects to investigate the river plume structure and suspended sediment dispersal patterns. Theoretical analyses were performed on the processes and mechanisms controlling the occurrence of an internal hydraulic jump, the interface geometry in the stratified flow, mechanical energy loss within the jump, and riverborne sediment dispersal pattern and its fate.

[60] The Herbert River plume was found to be characterized by a forced plume that experiences a transition from supercritical to subcritical via an internal hydraulic jump during ebb tides. The mode-1 internal Froude number derived from the TG equation was found to be inversely proportional to the squared water depth. This expression may be applied to quantitatively understand the fundamental characteristics of the cross-shelf dispersal of a river plume. Mechanical energy loss within the jump was primarily transferred to the potential energy driven by the buoyancy force, lifting the interface of the stratified flow. At the lift-off point where the river plume is detached from the bed, the bottom stress rapidly increased primarily due to the enhanced form drag. The critical thickness in the lower layer is inversely proportional to the bottom stress, and positively proportional to the flow rate in the lower layer. These findings would promote an understanding of the stratified flow behavior in the river plume.
[61] Intense stratification separated the water column into upper and lower mixed layers, and significantly decreased the bottom stress, resulting in weak resuspension of bed material. On the other hand, the internal hydraulic jump may enhance the mixing via the work induced by buoyancy forcing. Therefore, a separative sediment dispersal system occurred, forming upper and lower nepheloid flows seawards of the lift-off point. The sediment dispersal in the upper nepheloid layer satisfied an exponential decay law of the TSS versus the offshore distance. Comparison between the data and the exponential decay law indicated that the along-shelf dispersal and the difference in settling velocity may be two factors for the discrepancy. Both nepheloid flows spread seawards for a limited distance, but they have different mechanisms. Advective dispersal decay (dependent on the effective dispersal coefficient we defined) controlled the across-shelf dispersal in the upper nepheloid layer, while onshore baroclinic forcing restrained the seaward dispersal in the lower layer.

[62] A turbidity front (or a suspended sediment front) occurred in the river plume when the internal hydraulic jump formed. How the internal hydraulic jump causes the turbidity front needs to be further examined. Since no observations were conducted of any internal wave dynamics induced by the river plume, the relation between the jump and the internal wave is not yet clear. Neither is the mixing within the jump directly observed in our experiments, which should be important to develop a fully understanding of the jump dynamics and associated sediment dispersal behavior.

[63] Acknowledgments. Special thanks to Nathan Benfer of Griffith University, and David Abrego of James Cook University for turbidity and CTD profiling. We are grateful to the Queensland Department of Natural Resources, Mines and Energy for the river flow data. This study was conducted by the first author as a visiting scholar in Ocean Technology Group, University of Sydney. Great thanks should be given to Ian S. F. Jones for his kind invitation and financial support. The Challenger captain is an excellent skipper for shipboard observations. Three anonymous reviewers are greatly appreciated for their suggestive comments and thorough critiques. Financial support was given by National Natural Science Foundation of China grant 40306016 and the Australian Research Council grant DP0209275.

\section{References}

Anthony, K. R. N. (1999), Coral suspension feeding on fine particulate matter, J. Exp. Mar. Biol. Ecol., 232(1), 85-106.

Ariathurai, R., and R. B. Krone (1976), Mathematical modeling of sediment transport in estuaries, in Estuarine Processes, edited by M. Wiley, pp. 98-106, Elsevier, New York.

Armi, L. (1986), The hydraulics of two flowing layers with different densities, J. Fluid Mech., 163, 27-58.

Baines, P. G. (1984), A unified description of two-layer flow over topography, J. Fluid Mech., 146, 127-167.

Baines, P. G. (1996), Topographic Effects in Stratified Flows, 482 pp., Cambridge Univ. Press, New York.

Bartley, R., A. Henderson, I. P. Prosser, A. O. Hughes, L. McKergow, H. Lu, J. Brodie, Z. Bainbridge, and C. H. Roth (2003), Patterns of erosion and sediment and nutrient transport in the Herbert River catchment, Queensland, Consultancy Report CSIRO Land and Water, 59 pp., CSIRO, Canberra.

Belperio, A. P. (1983), Terrigenous sedimentation in the central Great Barrier Reef lagoon: a model from the Burdekin region, J. Aust. Geol. Geophys., 8(3), 179-190.

Belperio, A. P., and D. E. Searle (1988), Terrigenous and carbonate sedimentation in the Great Barrier Reef province, in Carbonate to Clastic Facies Changes, edited by L. J. Doyle and H. H. Roberts, pp. 143-174, Elsevier, New York.

Curran, K. J., P. S. Hill, and T. G. Milligan (2002), Fine-grained suspended sediment dynamics in the Eel River flood plume, Cont. Shelf Res. 22(17), 2537-2550. 
Drazin, P. G., and W. H. Reid (1981), Hydrodynamic Stability, Cambridge Univ. Press, New York.

Fabricius, K. E., and E. Wolanski (2000), Rapid smothering of coral reef organisms by muddy marine snow, Estuarine Coastal Shelf Sci., 50(1), $115-120$.

Farmer, D. M., and R. A. Denton (1985), Hydraulic control of flow over the sill in Observatory Inlet, J. Geophys. Res., 90(C5), 9051-9068.

Fischenich, C. (2001), Stability thresholds for stream restoration materials, EMRRP Tech. Notes Collect. (ERDC TN-EMRRP-SR-29), 10 pp., U. S. Army Corps of Eng. Res. and Dev. Cent., Vicksburg, Miss.

Fofonoff, N. P. (1985), Physical properties of seawater: A new salinity scale and equation of state for seawater, J. Geophys. Res., 90(C2), $3332-3342$.

Garvine, R. W. (1987), Estuary plumes and fronts in shelf waters: a layer model, J. Phys. Oceanogr., 17(11), 1877-1896.

Geyer, W. R., P. Hill, T. Milligan, and P. Traykovski (2000), The structure of the Eel River plume during floods, Cont. Shelf Res., 20(16), $2067-$ 2093.

Geyer, W. R., P. S. Hill, and G. C. Kineke (2004), The transport, transformation and dispersal of sediment by buoyant coastal flows, Cont. Shelf Res., 24(7-8), 927-949.

Harleman, D. R. F., and A. T. Ippen (1967), Two-dimensional aspects of salinity intrusion in estuaries: Analysis of salinity and velocity distributions, 158 pp., Comm. on Tidal Hydraul. Corps of Eng., U. S. Army, Vicksburg, Miss.

Hill, P. S., T. G. Milligan, and W. R. Geyer (2000), Controls on effective settling velocity of suspended sediment in the Eel River flood plume, Cont. Shelf Res., 20(16), 2095-2111.

Hoekstra, P. (1989), Buoyant river plumes and mud deposition in a rapidly extending tropical delta, Neth. J. Sea Res., 23(4), 517-527.

Hoyal, D., M. I. Bursik, and J. F. Atkinson (1999), Settling-driven convection: A mechanism of sedimentation from stratified fluids, J. Geophys. Res., 104(C4), $7953-7966$.

Johnson, K. S., C. K. Paull, J. P. Barry, and F. P. Chavez (2001), A decadal record of underflows from a coastal river into the deep sea, Geology, 29(11), 1019-1022.

Kineke, G. C., K. J. Woolfe, S. A. Kuehl, J. D. Milliman, T. M. Dellapenna, and R. G. Purdon (2000), Sediment export from the Sepik River, Papua New Guinea: evidence for a divergent sediment plume, Cont. Shelf Res., 20(16), 2239-2266.

King, B. (1994), Hydrodynamic complexities of tropical coastal waters: a study through the application of numerical models, Ph.D. thesis, Dep. of Phys., James Cook Univ., Townsville.

Kirby, R., and W. R. Parker (1982), A suspended sediment front in the Severn Estuary, Nature, 295(5848), 396-399.

Lambeck, A., and K. J. Woolfe (2000), Composition and textural variability along the $10 \mathrm{~m}$ isobath, Great Barrier Reef: evidence for pervasive northward sediment transport, Aust. J. Earth Sci., 47(2), 327-335.

Larcombe, P., and R. M. Carter (2004), Cyclone pumping, sediment partitioning and the development of the Great Barrier Reef shelf system: A review, Quat. Sci. Rev., 23(1-2), 107-135.

Larcombe, P., and K. J. Woolfe (1999), Increased sediment supply to the Great Barrier Reef will not increase sediment accumulation at most coral reefs, Coral Reefs, 18(2), 163-169.

Larcombe, P., P. V. Ridd, A. Prytz, and B. Wilson (1995), Factors controlling suspended sediment on inner-shelf coral-reefs, Townsville, Australia, Coral Reefs, 14(3), 163-171.

Largier, J. L. (1992), Tidal intrusion fronts, Estuaries, 15, 16-39.

Lawrence, G. A. (1993), The hydraulics of steady two-layer flow over a fixed obstacle, J. Fluid Mech., 254, 605-633.

List, E. J. (1982), Mechanics of turbulent buoyant jets and plumes, in Turbulent Buoyant Jets and Plumes, edited by W. Rodi, pp. 1-68, Elsevier, New York.

Marmorino, G. O., and C. L. Trump (1996), High-resolution measurements made across a tidal intrusion front, J. Geophys. Res., 101(C11), 25,66125,674 .

McCave, I. N. (1972), Transport and escape of fine-grained sediment from shelf areas, in Shelf Sediment Transport: Process and Pattern, edited by D. J. P. Swift, D. B. Duane and O. H. Pilkey, pp. 225-248, Van Nostrand Reinhold, Hoboken, N. J.

McCool, W. W., and J. D. Parsons (2004), Sedimentation from buoyant fine-grained suspensions, Cont. Shelf Res., 24(10), 1129-1142.

McCulloch, M., S. Fallon, T. Wyndham, E. Hendy, J. Lough, and D. Barnes (2003), Coral record of increased sediment flux to the inner Great Barrie Reef since European settlement, Nature, 421(6924), 727-730.

Mehta, A. J. (1989), On estuarine cohesive sediment suspension behavior, J. Geophys. Res., 94(C10), 14,303-14,314.

Milliman, J. D., and J. P. M. Syvitski (1992), Geomorphic/tectonic control of sediment discharge to the ocean-the importance of small mountainous rivers, J. Geol., 100(5), 525-544.
Mitchell, A. W., and M. J. Furnas (1997), Terrestrial inputs of nutrients and suspended sediments to the GBR lagoon, in The Great Barrier Reef Science, Use and Management, A National Conference Proceedings, vol. 1, Invited Papers, pp. 59-71, Great Barrier Reef Mar. Park Auth., Townsville.

Mitchell, A. W., R. G. V. Bramley, and A. K. L. Johnson (1997), Export of nutrients and suspended sediment during a cyclone-mediated flood event in the Herbert River catchment, Australia, Mar. Freshwater Res., 48 , $79-88$.

Morehead, M. D., and J. P. Syvitski (1999), River-plume sedimentation modeling for sequence stratigraphy: application to the Eel margin, northern California, Mar. Geol., 154(1-4), 29-41.

Moum, J. N. (1996), Efficiency of mixing in the main thermocline, J. Geophys. Res., 101, 12,057-12,069

Mulder, H. P. J., and C. Udink (1991), Modelling of cohesive sediment transport. A case study: the Western Scheldt estuary, in Proceedings of the 22nd International Conference on Coastal Engineering, edited by B. L. Edge, pp. 3012-3023, Am. Soc. of Civ. Eng., New York.

Nash, J. D., and J. N. Moum (2001), Internal hydraulic flows on the continental shelf: High drag states over a small bank, J. Geophys. Res., $106(\mathrm{C} 3), 4593-4612$

Neil, D. T., A. R. Orpin, E. V. Ridd, and B. F. Yu (2002), Sediment yield and impacts from river catchments to the Great Barrier Reef lagoon, Mar. Freshwater Res., 53(4), 733-752.

Nielsen, P. (1992), Coastal Bottom Boundary Layers and Sediment Transport, 324 pp., World Sci., Hackensack, N. J.

Nittrouer, C. A., and D. J. DeMaster (1996), The Amazon shelf setting Tropical, energetic, and influenced by a large river, Cont. Shelf Res., 16(5-6), 553-573

Nittrouer, C. A., G. J. Brunskill, and A. G. Figueiredo (1995), Importance of tropical coastal environments, Geo Mar. Lett., 15(3-4), 121-126.

Orpin, A. R., and P. V. Ridd (1996), Sediment distribution and transport mechanisms, Burdekin region, central Great Barrier Reef Lagoon, in Great Barrier Reef: Terrigenous Sediment Flux and Human Impacts, edited by P. Larcombe, K. J. Woolfe, and R. G. Purdon, pp. 128-144, CRC Reef Res. Cent., Townsville.

Orpin, A. R., P. V. Ridd, and L. K. Stewart (1999), Assessment of the relative importance of major sediment-transport mechanisms in the central Great Barrier Reef Lagoon, Aust. J. Earth Sci., 46(6), 883-896.

Parsons, J. D., J. W. M. Bush, and J. P. M. Syvitski (2001), Hyperpycnal plume formation from riverine outflows with small sediment concentrations, Sedimentology, 48(2), 465-478.

Rennie, S. E., J. L. Largier, and S. J. Lentz (1999), Observations of a pulsed buoyancy current downstream of Chesapeake Bay, J. Geophys. Res., 104(C8), 18,227-18,240

Soulsby, R. L. (1990), Tidal-current boundary layers, in The Sea, vol. 9 , Ocean Engineering Science, Part A, edited by B. L. Mehaute and D. M. Hanes, pp. 523-566, John Wiley, Hoboken, N. J.

Traykovski, P., W. R. Geyer, J. D. Irish, and J. F. Lynch (2000), The role of wave-induced density-driven fluid mud flows for cross-shelf transport on the Eel River continental shelf, Cont. Shelf Res., 20(16), 2113-2140.

Turner, J. S. (1973), Buoyancy Effects in Fluids, 367 pp., Cambridge Univ. Press, New York.

Walsh, J. P., and C. A. Nittrouer (2003), Contrasting styles of off-shelf sediment accumulation in new guinea, Mar. Geol., 196(3-4), 105125

Warrick, J. A., L. A. K. Mertes, L. Washburn, and D. A. Siegel (2004), Dispersal forcing of southern California river plumes, based on field and remote sensing observations, Geo Mar. Lett., 24(1), 46-52.

Wheatcroft, R. A., C. K. Sommerfield, D. E. Drake, J. C. Borgeld, and C. A. Nittrouer (1997), Rapid and widespread dispersal of flood sediment on the northern California margin, Geology, 25(2), 163-166.

Winterwerp, J. C., J. M. Cornelisse, and C. Kuiper (1991), The behaviour of mud from the Western Scheldt under tidal conditions, 14 pp., Delft Hydraul., Netherlands.

Wolanski, E. (1994), Physical Oceanographic Processes of the Great Barrier Reef, 194 pp., CRC Press, Boca Raton, Fla.

Wolanski, E., and M. Jones (1981), Physical properties of Great Barrier Reef lagoon waters near Townsville. I. Effects of Burdekin River floods, Aust. J. Mar. Freshwater Res., 32(3), 305-319.

Wolanski, E., and S. Spagnol (2000), Pollution by mud of Great Barrier Reef coastal waters, J. Coastal Res., 16(4), 1151-1156.

Wolanski, E., K. Marshall, and S. Spagnol (2003), Nepheloid layer dynamics in coastal waters of the Great Barrier Reef, Australia, J. Coastal Res., 19(3), 748-752.

Woolfe, K. J., P. Larcombe, and L. K. Stewart (2000), Shelf sediments adjacent to the Herbert River delta, Great Barrier Reef, Australia, Aust. J. Earth Sci., 47(2), 301-308.

Wright, L. D. (1995), Morphodynamics of Inner Continental Shelves, 241 pp., CRC Press, Boca Raton, Fla. 
Wright, L. D., and C. A. Nittrouer (1995), Dispersal of river sediments in coastal seas - six contrasting cases, Estuaries, 18(3), 494-508.

Wright, L. D., C. T. Friedrichs, S. C. Kim, and M. E. Scully (2001), Effects of ambient currents and waves on gravity-driven sediment transport on continental shelves, Mar. Geol., 175(1-4), 25-45.

L. Ametistova, FRECOM Ltd, Letnikovskaya Str. 9, Moscow 115114, Russia. (lametist@hotmail.com)
M. Heron and P. Kalangi, Marine Geophysical Laboratory, James Cook University, Townsville, Qld 4811, Australia. (mal.heron@jcu.edu.au; patrice.kalangi@jcu.edu.au)

C. J. Lemckert, Griffith School of Engineering, Griffith University Gold Coast Campus, PMB 50 Gold Coast Mail Centre, Qld 9726, Australia. (c.lemckert@griffith.edu.au)

J. Wu, State Key Laboratory of Marine Geology, Tongji University, Shanghai 200092, China. (jesse-wu@tongji.edu.cn) 